\title{
HISTORIA
}

\section{El actual Edificio de la Universidad de Sán Marcos}

\author{
DOI GRED IBSCHER \\ DANIEL YALCARCEL \\ NOTA PRELIMNAR
}

El presente artículo consta de dos partes: la primera es una reseña histórica y una descripciés actual, cuyo compiemento constitúyelo un inicial derratero eurístico y unas ilustraciones topográficas, acerca del local que ocupa hoy la Universidad Nacional Mayor de San Marcos de Lima, escrita por ción de las figurag simbelos tradicción de leyendas latinas y otras complementarias particularidades del techo y anexos del virreinal Salón de Actos académicos de la Facultad de Letras de la decana Universidad limeña y americana, escrita por la Dra. Gred Ibscher. Esta parte del trabajo está acompañada por láminas, habiéndose conservado los primitivos colores que muestra actualmente el techo del Salón de Grados de la mencionada Facultad.

\section{NOTICIA HISTORICA DEL ACTUAL EDIFICIO DE LA UNIVERSIDAD DE SAN MARCOS}

$$
\text { por Daniel Valcárcel }
$$

\section{INTRODUCCION}

En su casi cuatricentenaria historia, la muy limeña Universidad Nacional Mayor de San Marcos (indiscutiblemente, la más antigua Univer 
sidad Real y Pontificia de América) ha ocupado, en total çuatro diferentes locales: tres fueron les distintos edificios que albergafon a la Açademia limeña durante el siglo $\mathrm{XVI}_{i}$ un cuarto y último local le sirvió de novísima sede desde la segunda mitad del siglo XIX, lugar donde se encuentra ubicada hasta nuestros días.

El primitivo local de la antigua Universidad limeña fué el Convento de Nuestra Señora del Rosario, perteneciente a la Ordien de Santo Domirgo, cuando todavía este Centro superior de estudios no había recibido en nombre del evangelista San Marcos y se le conocía simplemente como la Universidad o Estudio General de la Ciudad de los Reyes. Su segundo local estuve easi a extramuros en la pafte de San Marcelo. donde poco antes había funcionado el Convento de la Orden de San Agustín, edificio al que se trasladó en 1574 la promisora y ya: Real y Pontificia Universidad, con a propósito de lograr su completa emaneipación de la Orden de los dominicos, sendueña de un local propio y desarrollar una vida acadếmica nuevas Euéen dicho año donde la Univerzidad sacó por sortea y poco después juró como Patrono suyo a San Marcos, tras de haber eqtado a punto de tomar el nombre de San Lucas, (como se coligo por la le rura de las primtivas Constituciones, enviadas por el Claustro al virrey Don Francisco de Toledo en 1571). Habían transcurrido døg años, en 1576 , quando la Universidad de San Marcos se trasladó a sut tefcer lozgl coue senta el detinitivo durante la época virreinal. Era éfte un edifficio gitado en fis frimitiva Plaza del Estancque (conocida después como la Plaza de la Inquisición), denominado de San Juan de la Penitencią, lugar erigido para dar asila a las Muchachlas mestizas "cuya honestidad peligraba"y que luego se transformó en depósito donde se recibía a las Mujeres easadas, alejadas de sus Maridos por disø̧ustos domésticos. Aquí permaneció la Universidad cesde el último cuarto del siglo XVI hasta la segunda mitad del siuglo XIX. Fúe durante el gabierno de Don Manuel Pardo (1872-1876) cuando se legalizó el traslado de la Universidad de San Marcos al local del antigua Convictoria de San Carlos. Y es en este lugar donde permąnece hasta nuestros días, cercana ya la celebración del Cuarto centenar:o de su fructífera y continuada vịda ađadémlca.

Objeto principal del presente artículo es bosquejar una inicial descripción histórica de este último local, señalando los tres cambios institucionales habidos desde su fundación a comienzos del sịglo XVII: priniøro, como sede del Noviclado o Casa de Probación de-la Orden de 


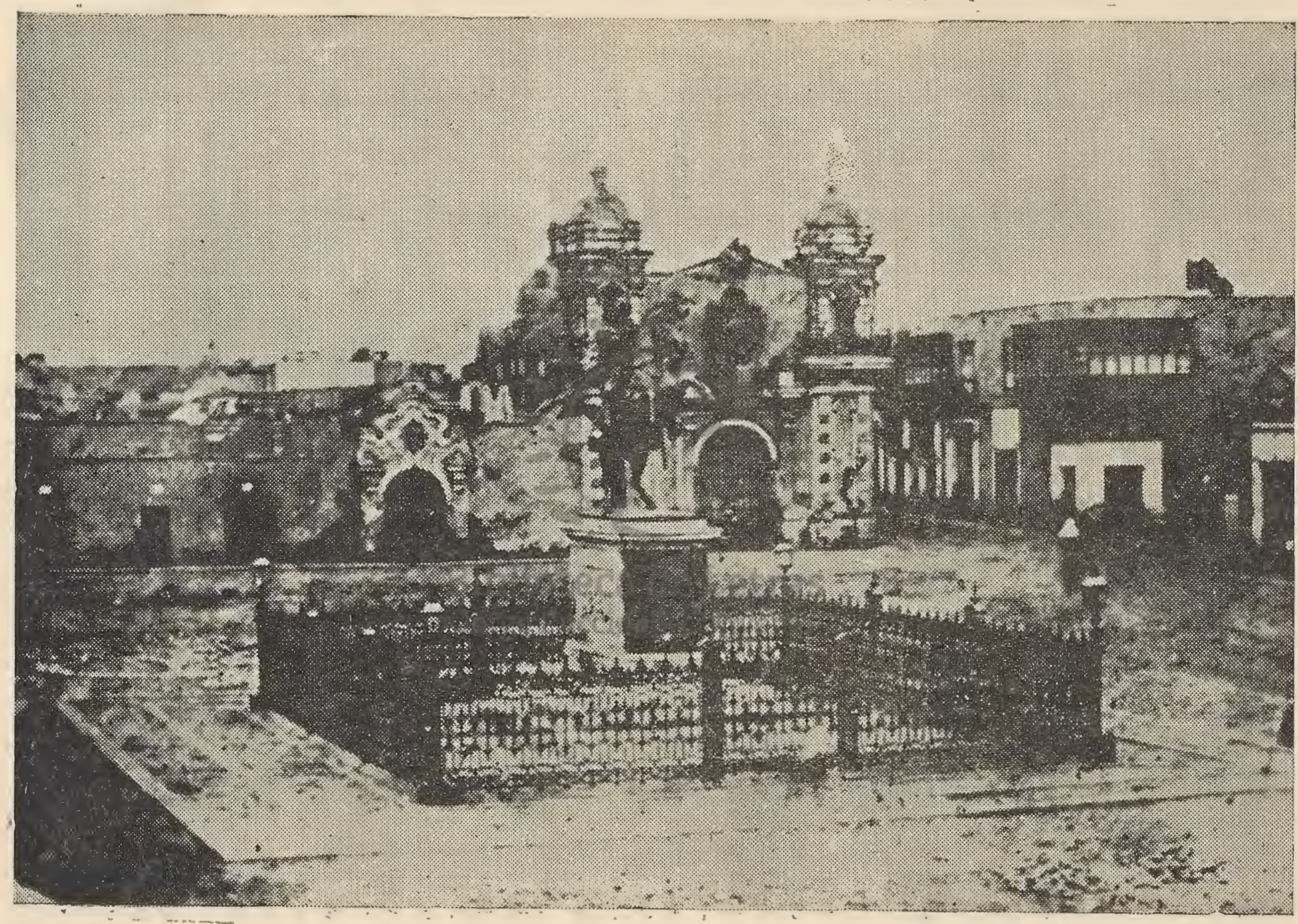

Fachada de la Universidad de San Marcos (al fondo). Plaza de la Inquisición. 
San Ignacio de Loyola (siglos XVII-XVIII); segundo, como sede del Real Convictorio de San Carlos (siglos XVIII-XIX); y tercero, como- sede de la Universidad Mayor de San Marcos, a la que se añadió la denominación de Nacional, o como ahora oficialmente se la denomina: Universidad Nacional Mayor de San Marcos (siglos XIX-XX).

\section{BIBLIOGRAFIA SUMARIA DE LA INTRODUCCION:}

SEMBLANZA DE LA UNIVERSIDAD DE SAN MARCOS por Diego de León Pinelo (1648). Trad. latín por L. A. Eguiguren). Lima 1949.Cap. II, pp. 45-47; Cap. X, pp. 62-65; Cap. XIII, pp. 77-78.

TESOROS VERDADEROS DE LAS INIIAS por Fr. Juan Meléndez ( 3 ts.). Roma 1681-82. T. I., Lib, I, Caps, VIII-X, pp. 49-76; Lib. II, Cap. X, pp. 180-87; Lib. V, Cop. Iy; pp. 586-48.

HISTORIA DE LA UNIVERSIDAD DE SAN MARCOS por Fr. Antonio de la Calancha. (Pub. L. A. Eguiguren). Lima 1921.- Partes 2، 7. pp. 6, 8.

HISTORIA DE LA FUNDACION DE ZIMA por P. Bernabé Cobo. (Pub. M. Gonzáles de la Rosa). Lima Itoo- Lio. II, Cap. XX, pp. 231; Lib. III, Cap. IX, pp 1274 i

HISTORIA DE LA FURBACAN, PROGRESOS, LIASTUA ESTADO DE

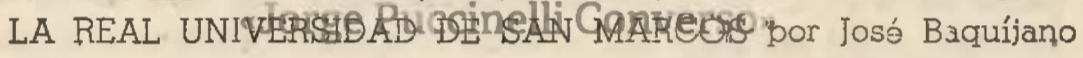
y Carrillo?.- Mercurio Peruano, T. II, No 53, Lima 7-VII-791, pp. $163-6.5$.

BOSQUEJO HISTORICO DE LA FUNDACION DE LA INSIGNE UNIVERSIDAD MAYOR DE SAN MARCOS DE LIMA, DE SUS FROGRESOS Y ACTUAL ESTADO por José Dávila Condemarín. Lima 1854, pp. 6, 8-10.

ALMA MATER por Luis Antonio Equiguren. Lima 1939, pp. 96-99, 123 24, 183-202, 279-88, 290-92, 394-96.

DICCIONARIO HISTORICO-CRONOLOGICO DE LA REAL Y PONTIFICIA UNIVERSIDAD DE SAN MARCOS Y DE SUS COLEGIOS por L. A. Eguiguren. Lima 1940. T. I, pp. 46-47, 87, 121 175-76.

LA UNIVERSIDAD Y ESTUDIO GENERAL DE LA CIUDAD DE LOS REYES EN SU PRIMER PERIODO por P. Domingo Angulo. - Revista Histórica, Lima 1939, t. IX, entr. IV, pp. 396-97. Ibid. 1939, t. XII, pp. 161-62, 171-75. 
LA FUNDACION DE LA UNIVERSIDAD DE SAN MARCOS por Mariano Per̃a Prado. Lima 1936, pp. 7, 17-18, 21-23.

LA UNIVERSIDAD DE SAN MARCOS DE LIMA por Manuel Vicente ViIlarán. Lima 1938, pp. 10, 19-20, 25-26.

NOTICIA SOBRE LA UNIVERSIDAD NACIONAL MAYOR DE SAN MARCOS por Daniel Valcárcel en "Almanaque Cultural Peruano", Lima 1948, pp. 319-322.

IGLESIA' DE SAN CARLOS por Teresa Accinelli, en "Lima Precolombina y Virreinal", Lima 1938, pp. 309-18.

v. la reseña de inéditos del Arehtvo Central "Domingo Angulo" de la Universidad de San Marcos, en la Bibliografía sumaria de la parte III.

NOTICIA HISTORICA DEL LOCAL DE LA UNIVERSIDAD DE SAN MARCOS

El actual edificio de la Universidad de San Marcos ha cobijado a to largo de su historia a tres instituciones diferentes: I) a comienzos del siglo XVII y paffei pel siste XKIIGpertenepié-a da Orden de San Ignacio de Loyola, III desdo la segura mitad del siglo XVIII hasta la segunda mitad del siglo xix albergo at famoso Convictorio de San Carlos, y III) desde entonces hasia el momento actual es la sede oficial de la Universidad de San Marcos. Cabe reseñar aquí el edificio en su aspecto presente. (Necesario sería además, un trabajo arquitectónico-histórico, que plantease y resolviese problemas esotéricos para la historiógrafo).

\section{I) El Noviciado de San Antonio de Abad}

El primitivo Noviciado o Casa de Probación de los Iesuitas estuvo ubicado en el Colegio de San Pabio. En 1592 el P. Provincial Juan Sebastián decidió erigir un Noviciado en parte distinta. A comienzos del mes de febrero del siguiente año, pasaron los Novicios a la Casa de Santiago del Cercado; pero como el lugar resultase harto estrecho, resolvieron mudarse a la huerta de San José, cerca del ría, inauqurándalo el año 1599. Coom el clima era bastante malsano, decidieron retornar a la Casa del Cercado apenas transcurridos tres años. Estaban así las cosas, 
cuando en 1605 el piadoso y acaudulado peninsular Don Antonio Corree Ureña donaba a los Jesuitas la suma de 70,000 pesos para lä erección del Noviciado definitivo. Sus restos reposan a la entrada del actual Panteón de los Próceres (antigua Iglesia de San Carlos), bajo una lápida ubicada al lado derecho, que dice: "Fundado: Antonio Correa".

Al ocuparse de los tiempos iniciales de la ciudad de Lima, el P. Bernabé Cobo trae una descripción del Noviciado limeño, que a la letra dice: "Otra casa tienen en esta ciudiad los Religiosos de la compañía de Jesús intitulada San Antonio de Abad, que es su noviciado; fundóse el año de mil seicientos seís por el mes de Agosto; está en la misma calle que atraviesa con el colegio de San Pablo, ocho cuadras distante de la plaza; fué su fundador Antorio Correa, hombre principal y muy rico, que espendía sus grandes riquezas en semejantes obras pias y dotola en tres mil pesos de renta. Tiene esta casa muy espaciosa, sitio de mas de cuatro cuadras, una lglesla (1) muy curiosa y ricamente labrada. cuya capilla mayor está cubjerta de una modia naranja labrada de artesones de cedro, con fan gran primor y hermosura que no hay en todo el Reino de este genero otra que se iguale; tiene un muy suntuoso retabio en el altar mayor y muchos ornamentos ricos; el edificio de la casa y vivienda es anchuroso y bien labrado, con algunas piezas interiores principales comg son: una capllfa on que está el Santísimo Sacramento, el Telitorio y otras, $y$ una muy grande huerta trazada con lucido órden en celles y equateles, eon tría hermosa capilla (2), en medio estanque $y$ fuente, con dos acequias muy copiosas de aqua clara y limpla que pasan por ella y la riegan: está pobladade cuantos géneros de árboles frutales y flores nacen en esta tierra. Residen ordinariamente en esta casa entre antiguos y novicios cincuenta Religiosos (3). Hasta aquí la descrípción del P. Cobo.

La ubicación del Noviciado puede verse en un "Plano de la Ciudad de Lima o de los Reyes, Capital del Perú", correspondiente al siglo

(1) LOS JESUITAS DEL. PERU, por Rubén Vargos Ugarte S. J., pp. 18i-82. v.PEQUENA ANTOLOGIA DE LIMA, pub. Raúl Porras, pp. 29, donde señálage be primitiva erección de la Iglesia de "San Carlos, en 1597".

(2) Alude a la Capilla de Ntra. Sra. de Lareto factual Salón de Grados de la Facultad de Letras de la Universidad de San Marcosl, descrito en la parte segunda do este artículo por la Dra. Thscher.

(3) HISTORIA DE LA FUNDACION DE LIMA, por P. Bernabé Cobo, pp. 274. 


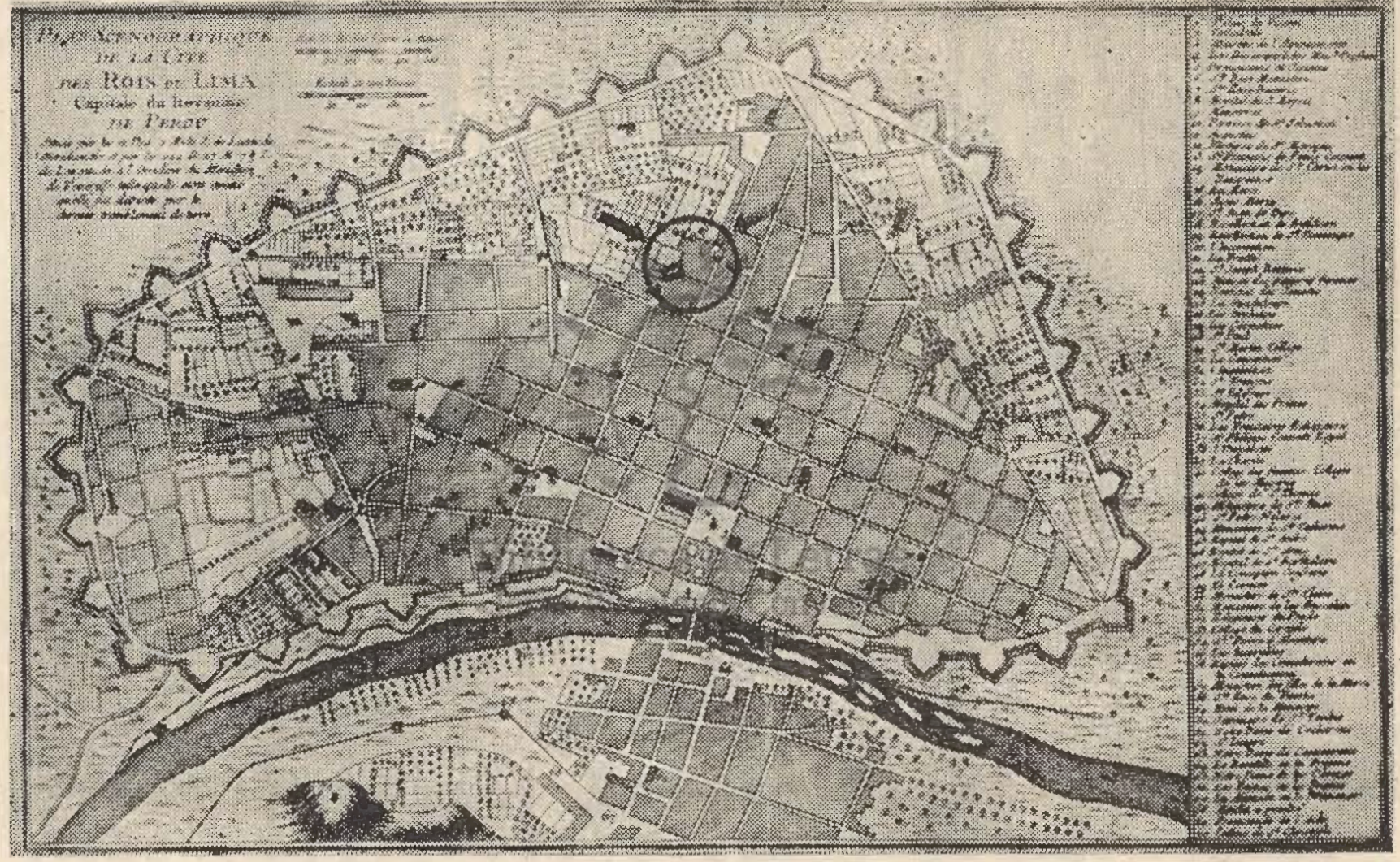

(Ilustración N? 2) Plano de Lima de mediados del siglo XVIII.

El círculo marca la ubicación del Noviciado de los Jesuitas (después Convictorlo de San Carlos) y hoy Universidad de San Marcos. 
XVIII, donde se nota la particular ubicación del edificio y su diferencia con otro correspondiente a la segunda mitad del siglo XIX (4). En cuanto a la Capilla de Nra. Sra de Loreto existe una genérica "Quenta y medida" de ella, donde se anotan las diferentes medidas, ilustrada por un croquis dividido en seis partes $(A-F)$ y algunas anotaciones finales (5).

El edificio resistió bien los movimientos sísmicos, frecuentes en la épocà virreinal; pero al producirse el famoso terremoto de 1746, el edificio del Noviciado quedó tan ruinoso que su reparación vino a constituir una verdadera reconstrucción. Recuérdase el año de 1758 como fecha de la reedificacićn de la Iglesia de San Carlos, siendo Arzobispo de Lima, en vísperas de salir, Don Pedro Antonio de Barroeta y Angei (ya nombrado Arzobispo de Granada) y cuando su sucesor el Obispo de Popayán Don Diego del Corro aún no había ocupado la silla de la Ciudad de los Reyes (6). El actual local de San Marcos estuvo en manos de la Orden de San Ignacio hasta la expulsión de los Jesuitas, dado por Real Decreto en 27 de febrero de 1767 y Pragmática de dos de abril del mismo año. Prodújose entonces el famoso y muy discutido extrañamiento de la Orden, que dió como consecuencia un notable retroceso en los establecimientos educativos virreinales. En muchos casos la reorganización vendría de ex-discípulos de Ios Jesuitas, como ocurrió por ejemplo con el famoso presbítero tacneño Don Ignacio de Castro, Rector del Colegio de Sah Bernardozabad delCuscos.

En la madrugada delr día Inuevéndel iseptiembrecde 1767, el virrey Don Manuel de Amat nombró a los ejecutores del extrañamiento, yendo al Noviciado de San Antonio Abad el Fiscal Don Diego Holgado con el añadido propósito de indagar cuales eran los Novicios que ante tales novedades estaban dispuestos a separarse de la Orden. Era Rector del

(4) v. la jlustración n० 2 y compárese con la n० 3 (v. la nota $n^{\circ}$ 14).

(5) QUENDA Y MEDIDA DE LA So CAPILIA DE LORETO. Bíblioteca Nacional de Lima. (v. Boletín de la Bib. Nax. Lima 1944, Año I, no 2, en "Inventario de las Libros Y Manuscritos existentes en la Firección de la Biblioteca Nacional después del incendio", no 975, XXIX, pp. 128, denominada: "Planta y medida de la Santo Capill de Loreto. (una hoja manuscrita)". Este título está equivocado, pues no dice "Planta". sino "Quenta".

(6) r.EPISCOPOLOGIO DE LAS DIOCESIS DEL ANTIGUO VIRREINATO DEI PERU, por P. R. Vargas Ugarte, pp. 28. 
Noviciado el P. Fernando Doncel. Entre el Rector y Maestro de Novicios, su Ayudante, ios Hermanos Estudiantes, los Novicios Escolares, los Coadjutores y los Estudiantes Coadjutores habían en el edificio 50 personas, sin contar los 24 Esclavos para el servicio ordinario. Requeridos por las autoridacies, solamente dos Novicios decidieron seguir la suerte de la Compañía de Jesús y marchar al cestierro.

En oro y plata, confiscaron del Noviciado 24,000 pesos; en propiedades, las haciendas de Santa Beatriz, de San Jacinto, de Motocache, de San José de la Pampa y el Cbraie de Cacamarca en la provincia de Hưmanga. El 29 de octubre los Jesuitas eran embarcados en el navío "El Peruano" y zarparon desde el puerto del Callao. En este mismo Navío, años después, en 1784, f́ueron expatriados 23 condenados por los sucesos referentes a la rebelión del Cacique Túpac Amaru, entre los cuales estaban: Mariano Túpac Amaru (segundo hijo del Caudillo), Juan Bautista Túpac Amaru (medio-hermano del Caudillo, y autor de unas fama sas "Memorias"), su esposa Doña Susana Aguirre, y el francés Don Antonio Gramusset, quien con Antonio Alejandro Berney, su compatriota, prepararon un conato de independencia en la Capitanía General de Chile.

\section{BIBLIOGRAFIA SUMARIA DE LA PARTE I:}

HISTORIA GENERAI DE LA COMPANAA DE JESUS EN LA PROVINCIA DEL PERU. Anonima. (Pubirf lMareos S. T.9. Madrid 1944. - T. I, Intr. pp. 32; 1 a parte, cap. II, pp. 294-96; $5^{a}$ parte, cap. II, pp. 389-90.

HISTORIA DE LA FUNDACION DE LIMA por P. B. Cobo.- Lib. 3, cap. IX, pp. 274; Cap. XXVI, pp. 329-30.

Relation Du Voyage de la Mer du Sud eux cotes du Chily et du Perou, fait pendant les années 1712,1713 ef 1714 par M. Frezier. Paris 1732, pp. 206, planche XXVIII (Plan de la Ville de Lima).

MEMORIA DE GOBIERNO DEL VIRREY AMAT (1761-1776). (Pub. Vicente Rodríguez Casado y Florentino Pérez Embid). Sevilla 1947.- I parte, cap. 25, pp. 128-50.

IESUITAS PERUANOS DESTERRADOS A ITALIA, por R. Vargas U., Lima 1934.- Cap. II, pp. 25; Cat. de la Prov. del Perú, pp. 192 93.

LOS JESUITAS DEI PERU por R. Vargas U. Lima 1941.- Parte I, cap. 
II, ppo. 15; Cap. IlI, pp. 19; Cāp. VII, pp. 70.- Parte II, cap. VII, pp. 181-82; Cap. VIII, pp. 192-93.

\section{II) El Convictorio de San Carlos}

Después del extrañamiento de los Jesuitas, el local del Noviciado sirvió para que el año 1770 se erigiese el Convictorio de San Carlos, con arreglo a la Real Cédula de 9 de julio de 1769, refundiéndose en el nuevo plantel los Colegios de San Martín y de San Felipe y San Marcos, fundados en la segunda mitad del siglo XVI. A fines del siglo XVIlI, San Carlos pertenecía a la jurisdicción del Cuartel IV, Barrio IX; pero a comienzos del siglo XIX estaba considerado en el Barrio X, formado por "la calle de Guadalupe, el Campanario del Noviciado, la Calle de San Buenaventura, la calle de San Juan Nepumuceno, la del Cascajal, la de Ortiz, Juan Simón, Puerta Falsa de Belén y el Barrio de la Venturosa" (7). Por entonces, el virrey Gil de Taboada y Lemus (1790-1796) quitó a San Carlos la huerta que daba a la Casa de la Chacarilla, lugar dedicado al necesario esparcimiento de sus Colegiales.

En el "Libro XIV" de Claustro" de la Universidad de San Marcos, señálase que el Colegio de San Carlos estaba "retirado dies quadras de esta Real Escuela (8); puesto allá en el que era Casa de Noviciado de los Jesuitas hacia los arrabales de la portada de Guadalupe".

La época de mayor prestigie del Convictorid Carolino fué durante el Rectorado de Don Toribio Rodríguezideo Mendoza (desde fines del siglo XVIII hasta comienzos del siglo XIX). Existe una muy importante descripción del edificio, al efectuarse un "reconocimiento del Colegio", el día ocho de noviembre de 1815. De acuerdo con un oficio del día anterior, hizo la Visita el Dr. Don Manuel Pardo Rivadeneyra, Regente de la Audiencía del Cusco, acompañado por su Secretario. Lo recibió el Rector, pero por indisposición suya acompañó a los visitantes oficiales el Vice-rector Dr. Matías Pastor. De inmediato "pasó a hacer el reconocimiento de lo material del expresado Colegio, a cuya entrada (9) se

(7) LAS CALLES DE LIMA por Multatuli (L. A. Eguiguren), t. I, pp. 224.

(8) Aludo a la Universidad de San Marcos, ubicada por entonces en la Plaza de la Inquísición (v. Libro XiV de Claustro, 1. 9 v.).

(9) La entrada principal era por la Plazuela de San Carlos, en cuya parte alta estaben las habitaciones del Rector. 
presenta un claustro de regular extensión, con altos, a la derecho del cual se halla una pieza de bastante capacidad que abraza casi todo el ángulo , destinado a Biblioteca, completándolo una entrada a la Iglesia, y otra a la Sacristía que llaman del Noviciado; en el ángulo siguiente se hallan dos piezas de bastante capacidad, ocupada la segunda por el Vice-Rector del Colegio: en el tercer ángulo se presenta primero la entrada a las claustros interiores, y luego habitaciones de Colegiales de regular capacidad hasta el cuarto ángulo que acaba en la escalera del claustro de arriba cuyos tres ángulos contiene habitaciones para cole giales, y el del frente una de bastante capacidad destinada para el Rector, la que concluye con una escalera reservada que termina en el Pórtico que se halla a la entrada del tercer ángulo de abajo: ' Este se abre en un claustro, sin altos de bastante extensión, y a la derecha de su entrada principal con el pasaje a otro segundo claustro del mismo tamaño; están divididos estos dos claustros por la capilla, y Sacristía del Colegio, bien aseada, y con capacidad. El tercer ángulo del primer claustro concluye con una portada que se abre en un patio pequeño con su Pila de Piedra en medio y de comunicación a la cocina, y oficinas que corresponden a sus lados e interiores, y también a otra Portada de Refectorio que ocupa todo el ángulo cuarto de este claustro primero con el que tiene asimismo comunicación; Los demás ángulos de uno y otro claustro están llenos de habitaciones pequeñas. Al principio del tercer ánguloedeadicho claustra está la entrada a un claustro pequeño baśtante demolidolyi futnosor que tiene algunas celdas pequeñas, y cuatro Aulas muy cortas, incómodas, y sin asientos casi, el de la izquierda de sus cuatro ángulos' no tiene habitación a]guna, y el del frente termina en una Aula de regular capacidad decen. re, y con sillería para los actos y funciones de Pomp;a del Colegio* (10). Hasta aquí el texto de la Visita de 1815.

Refiriéndose a los tiempos de Rodríguez de Mendoza, Jorge Guillermo Leguía ha hecho una descripción, que puede servir para una mejor comprensión de los documentos sobre el tema y una más ade cuada intuición del local, cuyo tenor es como sigue: "En la parte meridional de la ciudad; en la calle, que en dirección a la portada de Matamandinga o Guadalupe, seguía a la de Nuestra Señora de los Huérfanos; circundada por muros elevados, levantábase la Casa de Probación

(10) LA VISITA DE SAN CARLOS, Rev. Histórica, T. XVII, pP 195-96. 
de San Antonio Abad, que conocían iodos los limeños con el nombre de Noviciado de los Jesuitas. Macizo, amplio, lleno de luz, era el ed:ficio. En el lado de la calle del Novíciado, y paralelos a ella, se extendían dos dilatados patios, llamados el exterior, de los Naranjos, y el interior, de los Jazmines, divididos por la capilla de Nuestra Señora de Loreto. Hacia la actual calle Inambari, que no existía por entonces, y en comunicación con el de los Naranjos, había otro patio, que se denominaría de los Manteístas o Capistas (I1) en los días de don Bar. tolomé Herrera. A estos patios daban las puertas labradas de las espaciosas estancias de los hermanos de la Compañia, alumbradas y ventiladas por sendas ventanas teatinas que absorvíar las brisas frescas del sur. En el centro de cada patio erigíase, una pila, en cuya fuenta murmuraba perennemente el agua con que se regaba las plantas y flores circundantes. Dominando los claustros, y comprendida entre el ángulo diedro formado por el patio de los Naranjos y de los Manteístas, surgía la mole de la pequeña Iglesia de San Carlos, cuya rechoncha torre cuadrada presentaba sus bronces Iesonantes frente a la calle denominada por ello del Campanario, y que hoy se conoce con el nombre de Gallinazo o Monzón. Rodeando la casa y la iglesia de los Jesuítas por norte, oriente y mediodía se hallaba la huerta de los hermanos de Loyola" (12). Hasta aquíi J. G. Lequía.

Allá por los años de 1825 era Rector de San Carlos Don José Manuel Pedemonte, quieh pidió se restituyese Ra huerta que años atrás había quitado al Colegio de manera arbitraria, el virrey laboada y Le mus. En respuesta a sus afanes se ordenaba, al año siguiente, que eì Director de Censos hiciese la entrega "sino se ofrece inconveniente" (13).

En el Margesí de 1853, del Colegio de San Carlos, existe otra importante descripción del local, que literalmente transcríbese: "Contiene la plazuela de este nombre, la puerta general con sus serraduras (sic), llabes corrientes, en ella la puerta interna de postigo por la que se entra al patio del primer claustro con sus respectivo arco circuído de pinos altos y bajos con entrada a la Sacristía de la Yglesía pública y otra que hubo de almacén con dos escaleras y otra escalera para entrar

(11) A éste se le llamó también patio "do los Machos".

(12) EL PRECURSOR por J. G. Leguía, pp. 8-9.

(i3) LAS CALLES DE LIMA por L. A. Equiguren. T. II pp. 263. 
al interior del Colegio. El patio general está adornado de veinte y ocho columnas de madera gruesas con otras tantas bancas de piedra, encima un alto con aposentosi para el Rector y los Maestros con sus puertas, ventanas y cerraduras corrientes. En este alto hay tres corredores con treinta columnas de madera y sus varandillas: El otro corredor con quin. ce columnas de lo mismo. En el interior del Colegio han un tráncito al inmediato patio con 28 marcos sobre columnas de madera de bálsamo circuído de viviendas con sus puertas, ventanas y cerraduras corrientes, con una pueria colateral de la Capilla interior de Nuestra Señora de Loreto con adornos de perfiles de oro; otro departamento de la librería común, otro colateral del refectorlo con adomos y otro de la enfermería. Sigue otro departamento del tránsito del refectorio como para el patio que sirve para las comunes de la Casa, con sus divisiones y puertas y pilas corrientes de agua: Otro en el tránsito que va para la huerta y un local para guardar los fracmentos (sic) de la Iglesia. En el medio de este patio se be (sic) una pila de jaspe blanco circulda de la misma piedra y de otro ordinario, con el agua corriente que comunica al tercer patio. Hay dos puertas falsas que ocupa el Superior de la Casa y en su frente un Nichó enbebido (sic) para la Yglesia pública". Hasta aquí la descrioción de Margesí.

El área del ConvictoribCáalino permanedió sin sufrir modificaciones hastā el año de 1857J cuando los señores Mariano Felipe Paz Soldán, Pedro Sayán y Mariano Alvarez formaron una sociedad con el propósito de urbanizar los terrenos pertenecientes a las huertas del Colegio. Fué entonces que se abrieron las calles de Inambari y de Cotabambas, tomando el plantel una conformación distinta y reduciéndose su extensión primitiva.

BIBLIOGRAFIA SUMARIA DE LA PARTE II:

LIBRO XIV DE CLAUSTRO (Universidad de San Marcos), Archivo Central "Domingo Angulo", Estante X, t. 1, № 705, f. 9v. (Versión por Daniel Valcárcel).

LA VISTTA DEL COLEGIO DE SAN CARLOS POR DON MANUEL PARDO (1815-1817) Y SU CLAUSURA DE ORDEN DEL VIRREY PEZUELA (1817). Pub. Raúl Porras Barrenechea). En Revista Histórica", t. XVII, Lima 1948, pp. 195-96. 
LIBROS DE GASTOS DEL CONVICTORIO DE SAN CARLOS. Arch. Central "Domingo Angulo", Sala I, Estante Z, Nos. 679, 680, 681, 682 , 683, 684, 685, 686, 687, (v. Catálogo pp. 89-90).

MARGESI DEL ANTIGUO CONVICTORIO DE SAN CARLOS 1853. Arch.

Cntr. "D. A.", Sala I, Est. Z, No 688 (v. Catálogo pp. 90-91).

EL PRECURSOR por Jorge Guillermo Leguía, Lima 1922, pp. 8-9.

SAN CARLOS EN LOS DIAS DE HERRERA por J. G. Leguía, en el "Boletín Bibliográfico de San Marcos", No 15 Lima 1924, pp. 198, 200-01.

LAS CALIES DE IIMA, por Mulátuli (L. A. Eguiguren), Lima 1945-46.T. I, pp. 178, 224-26, 229. T. Il, pp. 263.

\section{1) Là Universidad Mayor de San Marcos}

Proclamada la independencia, el primen Congreso ocupó parte del local de San Marcos. Esta anómala situación continuó con detrimento de la Universidad. En el Reglamento dado a San Marcos en 1861, se ñálase cinco Facultades: Teología, que funcionaría en el Seminario Conciliar; Jurisprudencia, Filosofía y Literatura y Matemáticas y Ciencias Naturales que funcionarían en el Colegio de San Carlos; y Medicina que funcionaría en la Escuela delcnisme nombrea. Si Colegio de Guadalupe quedaba dedigado aplac"Instrucción Miedia", Desde entonces San Carlos pasó a ser una depedencia de la Universidad de San Marcos. Esto ratifícase por el rol de la Junta Directiva de dicha Universidad, correspondiente a 1862, donde aparece integrándola el Dr. Juan Gualberio Valdivia, Rector de San Carlos. Como necesaria consecuencia, en 14 de mayo de 1862 fueron oficialmente incorporado como Doctores de San Marcos los Prefesores del Colegio de San Carlos que enseñaban en las Facultades de Jurisprudencia, de Filosofía y Literatura y de Matemáticas y Ciencias Naturales. Cosa análoga se hizo con los Profesores de la Facultad de Medicina, en dos de julio de 1853. Este carácter universitario le fué ratificado a San Carlos en 1866, llamúndose a sus Facultades: Derecho, Letras y Ciencias (14).

Al año siguiente, en 1867 " los continuos y enojosos problenas que se suscitaban entre las Secretarías de las Cámatas y San Marcos produ-

(14) v. EL PERUANO, 16-III-866, pp. 101-02.

v. ilustración $n^{\circ} 3$ y compárese con la $n^{\circ} 2$ (v. la nota n० 4). 


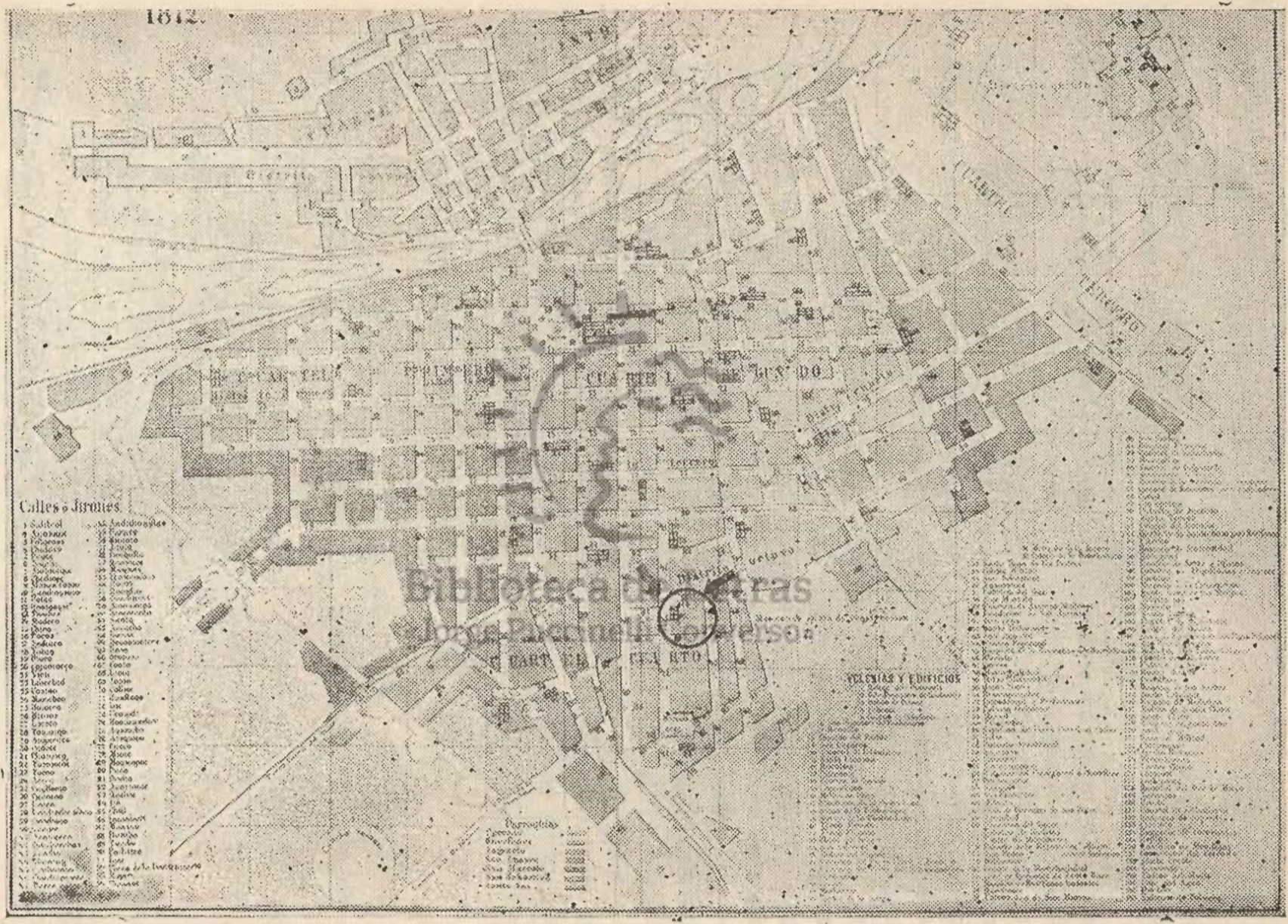

(Ilustración N? 3) Plano de Lima por P. V. Jouanny (1872)

El círculo señala la ubicación actual de la Universidad de San Marcos. 
jeron urıa situación harto embarazosa. Con el fin de solucionarla se daba una resolución suprema, que firma el 25 de enero de dicho año el Ministro José Simeón Tejeda, ordenando cómo "mientras duren las sesiones del próximo Congreso se traslade la Universidad al Corivictorio de San Carlos, dejando para el uso del Congreso todo su local, por cuyo arrendamiento le abonorá la Tesorería doscientos soles mensuales, trasladándose igualmente al antiguo local de la Cámara de Senadores el Colegio de abogados y la Sociedad de Medicina que funcionan en dicha Universidad, a donde se trasladará también el archivo y mencío de la mencionada Cámara de Senadores" (15). La extinsión del Colegio de San Carlos y la definitiva ubícación de la Universidad de San Marcos se hizo durante el gobierno de Don Manuel Pardo (1872-1876), lugar donde se encuentra hasta el presente.

Años más tarde, durante la guerra con Chile, con fecha tres de diciembre de 1880 se designó para el acuartelamiento de los Batallones' de Reserva de Lima "el local de la Universidad Mayor de San Marcos, la Escuela de Medicina, el Colegio de Nuestra Señora de Guadahroe. y la Escuela Normal de Varones". Ocupadar Lima, la Universidad sirvió de Cuartel a los invasores. Firmada la paz ${ }_{\text {il }}$ arquitecto señor Trefogli, con fecha dos de noviembre de 1883, enviaba el siguiente Informe: "Conforme a lo acordado en la sesión que celebró la Junta, nombrada por el señor Rector de la Universidad Mayor de San Marcos, en 25 de octubre último, remito a Ud, el informe detallado del estado en que se encuentra el local de San Cárlos, como resultado del prolijo reconoc1miento que he practicado. Fachada del edificio.- Además de la cornisa alta que se ha aesarmada antesnad la Cocupacion," se ha quitado une de las ventanas y la puerta que dá al patio de externos ( $2^{\circ}$ patio). La primera se reemplazó con la puerta que se quitó a la Tesorería, y la segunda se tapeó, con ladrillos que se estrajeron de una pared que se derribó en el jardín de la Escuela de Ingenieros. Patio Principal o de Maestros. - La primera clase de Iurisprudencia, tiene empapelado en mal estado; á su puerta y ventanas le faltan herrajes y cuatro vidrios. La Tesorería está sin puerta, son las devisiones del cedro y los zócalos de madera. El empapelado está destrozado; se han quitado cuatro visa-

(15) Oficio del Despacho de Justicia, Instruoción. Culto y Beneficencia al Rector de la Universidad de San Marcos.- Archivo Central "Domingo Angulo" do la U.N.M. de San Marco8, Sala I, Estante I. Tomo 5, pp. 2. 
gras de metal á la mampara, á la que le falta un vidrio. El cuarto de Portero, tien su empapelado en mal estado. Los excusados están malogrados en sus divisiones; asientos y piso, y falta el lavatorio. Decanato de Ciencias Políticas. - Los empapelados de las tres piezas, de que se compone este local, están destruídos. El pedestal de madera de una de las piezas se ha quitado, así ccmo el zócalo de otra. Las puertas y ventanas no tienen los herrajes correspondientes; se ha quitado una ventana abriendo en su lugar puerta; á las mamparas se les han quitado cuatro visagras de metal y faltan alqunos vidrios. : Biblioteca.- Se ha quitado la estantería de cedro que corría alrededor de las paredes del salón principal; parte del zćcalo de la la. sala. Las paredes y pisos están maltratados; la puerta y ventanas no tienen sus herrajes completos y faltan diez y ocho vidrios. Salón de Químíca.- El techo, en su fondo, está maltratado á consecuencia de la cocina que se ha establecido en los altos. La puerta que dá al Gabinete de Mineralogía está tapeada. Las puertas maltratadas y faltas de herrajes. Patio $2^{\circ} \circ$ de Externos. - Facultad de Ciencias. - Gabinete de Mineralogía. - Está maltratado en sus paredes y piso. Se há abierto la pared en el respaldo, quitando la ventana. .Cuartos de siryientes y excusados, lavaderos, etc. - Están maltratados en sus paredes y pisos; falta una división de telar y cinco puertas; de los comunes y lavaderos nada queda. - Laboratorio de Química y Física.- Nada queda de aparatos fijos: sus paredes y pisos destrozados, Las puertas y ventanas sin chapas y destruídas una divisićn interior y dos puertas. - Salón de Dibujo.- Faltan las hojas de la mampara; "y patte de closin herrajesndellacpuerta y ventanas y algunos vidrios. Las paredes están maltratadas.- Clase de Historia Natural.- Este departamento ha seguido la suerte del salón de dibujo; además se le ha quitado una puerta de comunicación interior.- Generalidades.- El piso de los corredores está lleno de agujeros, así como el empedrado del patio: su puerta que dá á la calle está tapeada.- Patio de Naranjos. - Facuitad de Jurisprudencia - Los tres salones de clase que ocupan el respaldo, están destrozados; faltan tres divisiones; su piso de asfalto está arruinado; las puertas sin chapas; faltan dos lienzos del cielo raso y ocho vidrios. Los pisos de iadrillos de las cinco clases, menores, están en mal estado y sus puertas sin chapas.- Capilla.Faltan hojas de bastidores de las ventanas, cincuenta y siete vidrios y las chapas de las puertas; cuatro de las bancas talladas que estaban fijas a las paredes han desaparecido. Excusados.- Los antiguos excu- 
sizios han desaparecido y sus pisos y paredes están destrozados; al recipiente de cimiento armado y estanque le han quitado los asientos:Patio de Jazmines.- General.- Es la parte local que más ha sufrido. Se nota de menos: las dos escalinatas laterales y la mayor parte de los asientos de la la. hilera; los tramos de las escaleras que dán á la galería y parte de los balaustres y asientos de estas: los forros de madera de las paredes de los pasadizos que están debajo de la la. galería y de las escaleras han desaparecido en su mayor parte: la baranda que separaba del salón, los asientos de los Catedráticos y de todos las asientos y zócalos de esta parte del lodal no se encuetran, así como las de la galería alta de señoras. Las puertas de las gaierías y pasadizos no existen; maltratados y sin herrajes la puerta principal y ventanas que tienen rotos muchos vidrios. Los pisos estún destruídos en parte. Patio.- Los pisos están muy maltratados, la acequia atorada y descubierta en parte.- Excusiados.- El departamento de excusados está destruído en sus pisos, techos y asientos, sus conductos inutilizados. Las puertas maltratadas y sin los correspondientes herrajes. Clase.- El salón que dá al patio está muy destruido en su piso de asfalto; làs paredes maitratadas y sin los correspondientes herrajes las puertas' y ventanas. Altos.- Escalera.-Faltan los remates de los dos pedestales de la balaustrada y el lienzo del cuadro fijo a la pared dei descenso.- Decanato de Jurisprudencia y Secretaría de idem.- Los empapelados están maitratados, sin herrajes las puertas y ventanas, faltan ocho vidrios. Rectorado y Secretaría de idem.- Los zocalos de madera han sido quitados en su mayor parte, falta la mampara interior que divalrsalín; las puertas y ventanas son los correspondientes herrajes y con varios vidrios rotos. Facultad de Leiras.- Las cinco piezas que ocupa esta Facuitad tiene sus empapelados destrozados; faltan tres puertas de comunicación interior de madera de cedro y seis bastidores de ventanas; las demás puertâs y ventanas faltos de herrajes y con setenta y dos vidrios menos. El pasadizo que da comunicación con el mirador y los dos cuartitos de idem, tienen sus paredes $y$ pisos maltratados y las puertas rotas $y$ sin herrajes. Clases, (altos) patio de Naranjos. - El salón principal tiene destruída la división que lo separaba del siguiente; tiene maltratadas sus paredes, hay varios huecos en los pisos y faltos de herrajes las puertas. El saloncito que está en el respaldo tíene su piso, que es de asfalto, muy maltratado. Las dos piezas que están sobre la Sacristía, tienen destruídos sus empaeplados; faltan dos puertas y herrajes á la puerta y venta- 
Ma existente. - Facuitad de Cienciâs (altos) patio de Externos.- Gabinete de Física. - Las puertas están sin chapas; maltratadas las paredes y sacada una, tabla del piso. Patiecito anexo-- Convertido en una cocinería: está destruída la torta y malogrado parte del techo del salín de Quimica que está en los bajos; sus paredes están maltratadas y sin herraje la puerta. Sala de Matemáticas.- Sus tres puertas están sin chapas, el empapelado destruído, y el zócaio de madera, se le ha quitado, en su mayor parte. Sala de Sesiones. - Se encuentra en el mismo estado que la Sala anterior; faltan dos vidrios. Decanato de Ciencias y Secretaría de idem. - Los empapelados están inutilizados; los zócalos de las paredes han desaparecido; y las puertas y ventanas sin los correspondientes herrajes y vidrios. Corredor. - Faltan once balaustres de madera y hay algunos huecos en el piso. Mirador. - Falta la puerta de entrada y las demás puertas y ventanas sin los correspondientes herrajes; una mampara y un bastidor roto; faltan 29 vidrios. Servicio de Gas y Agua.

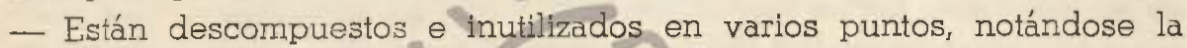
falta de varios aparatos. La acequia de desague está destrozada y obstruída; lo que ha dado lugar á varios aniegos que han causado bastante daño al edificio" (1E). Hasta aqu? el informe.

En la actual Sección de Fincas de la Universidad de San Marcus existen importantes documentos (véase la Bibliografía sumaria), uno de los cuaies denomínase: "Tasación de la Propiedad de la Universidad Mayor de San Marcos, situadalentrolas calles de Azángato (Noviciado), Inambari (Parque Universitario), Cetabambas destinada a local de la Universidad". Su texto completo es' el siguiente: "Ubicación.- Esta propiedad está ubi. cada con frente al lado Sur del Parque Universitario, girón Inambari, extendiéndose hasta la esquina que forma esta calle con el girón Cotabambas; y por el otro extremo tiene incluído el Panteón de los Próceres y continúa en la novena cuadra del girón Azángaro, llevando los Nos. 204 y 234, por Cotabambas; 482, 452 y 422, por Inambari y el No. 931 por Azángaro. Perímetro y linderos.- Frente al girón Inambari, Parque Universitario, con $106 \mathrm{ml}$. Derecha entrando con la Plazuela de S. Carlos con $9.70 \mathrm{ml}$. forma un martillo de $0.60 \mathrm{ml}$. que cierra el área, continúa con $13 \mathrm{ml}$., vuelve a cerrar el área en escuadra con $6.20 \mathrm{ml}$, vuelve a seguir hacia el fondo con 18.70, ensancha el área doblando hacia la calle de Azángaro con $5.80 \mathrm{ml}$. y vuelve a seguir hacia el fondo

(16) Anales, T. XïI, rp. $279-83$. 
con $7.20 \mathrm{ml}$. y vuelve a doblar a escuadra ensanchada el área y terminando en la cālle de Azángaro con $19 \mathrm{ml}$. donde éste punto tiene frente al girón Azángaro con una extensión de $46.20 \mathrm{ml}$. colindando los tramos anteriores con el Panteón de los Próceres. Izquierda con la calle de Cotabambas, con una extensión de $92.20 \mathrm{ml}$. Fondo, es una línea recta de dos tramos, el primero de $43 \mathrm{ml}$. colinda con la propiedad de la Sra. Bandini y el otro de $93.80 \mathrm{ml}$. colinda con la propiedad de Ballero Hermanos, con un total de $136 \mathrm{~m} .80 \mathrm{~cm}$. Area.- Se encierra dentro de los expresados perímetros y linderos un área de 11, $387 \mathrm{~m} 2$ (ONCE ML TRESCIENTOS OCHENTISIETE METROS CUADRADOS). Descripción y tábrica.- Este edificio está destinado a local de la Universidad y en él funcionan tanto las dependencias de administración, rectorado y decanatos, como las diversas facultades de que se compono, según se expresa en detalle en el plano adjunto.- Consta de dos plantas, ocupando la segunda la parte del área que se indica en el plano con los destinos que en las leyendas se anotan.- La construcción de los bajos es de antiguos y gruesos muros de albañilería en perfecto estado de conservación, incluyendo los claustros, con sus columnatas de caoba y roble. Los techos, puertas y ventanas de los bajos son en su mayoría de caoba y sólo de piro oregón algunas correspondientes a la Facultad de Letras.- Los pisos son de machihembrado en las aulas y oficinas; de locetas en los pasajes, patios y laboratorios, y de cemento en los pasajes interiores, claustros de letras, patios de jazmines, claustro y patio de la Facultad de Cienclas. Además por el lado de Cotabambas estarconstruidolel locap pararel gimnasio universitario, compuesto de gimnasio cubierto con techo a dos aguas y piso machihembrado de 1 x 3, campo de deportes, con canchas para BasketBall y piscina de natación de concreto con su servicio de agua y de sague independiente y departamento de vestuario, duchas y servicios higiénicos.- Los muros de las aulas, de los laboratorios, oficinas y dependencias están pintadas al óleo; los de los claustros, patios y pasajes a! temple; la carpintería y techos pintados al óleo.- En los sitios que marca el plano se encuentran los servicios higiénicos tanto para las oficinas como para el alumnado de las diversas facultades.- Los altos están construídos de telares, gruesos y antiguos en buen estado de conservación; pisos de machihembrados, excepto en los servicios higiénicos; vidrieras, divisiones de madera en buen estado de conservación sobre los claustros del patio de Letras y de Ciencias.- La mayoría de 
las aulas de los laboratorios tiene farolas con bastidores de vidrios $y$ rejas a fin de asegurar una perfecta ventilación y luz. Tanto los bajos como los altos tienen sus servicios higiénicos completos y cada Facuitad tiene sus circuitos y medidores independientes de provisión de luz y fuerza eléctrica.- En la tasación que a continuación se expresa no se ha considerado el valor que como reliquia histórica tiene el Salón de Grados de la Facultad de Letras. Tasación.- Valor del área.Apilcando el Reglamento y Arancel de Tasaciones vigente que marca los precios de Slo. 40.00 por Cotabambas; de $\mathbf{S} \mid 0.80 .00$ para el Parque Inniversitario; y de S/o. 80.00 por Azángaro, obtengo como valor del área la suma de 910,960 soles oro (NOVECIENTOS DIEZ MIL NOVECIENTOS SESENTA SOLES ORO).- Valor de la fábrica.- Tasando Câda cosa por separada según su estado y calidad incluyendo las instalaciones fijas al inmueble y $\sin$ considerar los anaqueles ni aparatos de diversa índole ni colecciones de especies zoológicas ni arqueológicas; obtengo como valor de la fábrica la suma de S!o. 700,000 (SETECIENTOS MIL SOLES ORO.-Vălor total.- Valor del área... Slo. 910,960.00. Valor de la fábrica... Sjo. 700,000.00. Valor total... S|0. 1'610,950.00. Son UN MILION SEISCIENTOS DIEZ MIL NOVECIENTOS SOLES ORO.-- Esta propiedad se encuentra en poder de la Universidad desde hace más de cuarenta años y todas las reparaciones y nuevas instalaciones efectuadas con posterioridad han sido ejecutadas con sus propios fondos sin que deba nada al respecto.- Lima, Octubre 25 de 1933. - Enriqua Rivero Tremouille. In Un sello que dice: Manuel E. Villarán.- Escribaño-ActuariocinLimaco Hastas aquí la Tasãción (v. Bíbliografía Sumaria de la parte III, no 2).

Gobernando Don Augusto B. Leguía, el año de 1924, la antigua iglesia del Noviciado y de San Carlos, sucesivamente, pasó a transformarse en el Panteón de los Próceres. La Iglesia sufrió una general restauración, construyéndose la actual Cripta. Entre los pernanos eminentes que reposan allí, cabe recordar a Don Hipjólito Unánue, uno de los grandes representantes de la cultura pernana de todos los tiempos y paradigma de nuestros estudiosos.

BIBLIOGRAFIA SUMARIA DE LA PARTE III:

ANALES UNIVERSITARIOS, pub. Dr. D. Francisco García Calderón. T. XIII. Lima, Imp. del Universo de C. Prince, 1887, pp. 80, 275-306 (contiene el Informe del arquitecto M. Trefogli). 
DOCUMENTOS DE LA SECCION FINCAS DE LA UNIVERSIDAD DE SAN MARCOS. Legajo № 3. 1) Finca entre las calles Cotabambas, Inambari y Azángaro. Local de la Universidad (2f́s.). Contiene: Certificación del Registrador de Distrito de Lima, Moisés Olivera Chávarri. Certifica sobre la primera inscripción de dominio de la finca "del antiguo Convictorio de San Carlos', hoy la Universidad, y pone algunos antecedentes históricos de su dominio. - 2) Tasación de la propiedad de la Universidad Mayor de San Marcos, situada entre las calles de Azángaro (Noviciado), Inambari (Parque Universitario) y Cotabambas, destinada a local de la Universidad ( $3 \mathrm{fs}$.). Contiene: Ubicación. Perímetro y linderos. Area. Descripción y fábrica. Tasación. Valor del área. Valor de la fábrica. Valor total. (Este documento ha sido transcrito íntegramente en la parte III). 3) Títulos de la finca situada entre las calles Azángaro, Inambari y Cotabambas (Local de la Universidad, propiedad de la Universidad Nacional Mayor de San Marcos (14 fs.). Titulación organizada en 1934. Lleva tres Planos o Mapas de la propiedad. 4) Reconocimiento de D. Enrique Rivero Tremouille sobre reconocimiento. Juez de Primera Instancia Dr. Ricardo Bustamante Cisneros. Enero 1934. Actuario: M. E. Villarán (l f f.).

REGLAMENTO GENERAL DE INSTRUCCION PUBLICA DE 1870, Cap. XXI, Administración dè Renlas, Art, 332 - Inciso 5\%. (Considera entra las rentas de la Universidad, las "que hubieren sido asignadas anteriormente a los establecimientos de instrucción superior, refundidos hoy en las Universidades").

RENTAS DE LA UNIVERSIDAD (6 arts.). Lima 15-VII-876. En "Leyes y Resoluciones vigentes en materia de Instrucción expedidas desde 1876". Recop. F. Ramírez. Lima, 1891, pp. 158.

RESEÑA DE INEDITOS SOBRE EL LOCAL ACTUAI DE SAN MARCOS (S. G., 52 ts.). Arch. Centr. "Domingo Angulo" U. N. M. de San Marcos, Sala I, Estantes I-V. (v. Catálogo, pp. 9-15). ESTANTEI: no 1, t. I, pp. 112, 116, 322-23, 765, 767; no 5, t. V, p.p. $2,23,115,146 ; n^{\circ} 6$, t. VI, pp. $23,38-44 ; n^{\circ} 9$, t. VIIC, pp. 212-13, 215, 224, 227-28, 294; no 10, t. VIII, pp. 63, 516. ESTANTE II: no 11 , t. IX, pp. $38,45,48,55-56,74,128,663-84$; no 12 . 
con otros $(A, B, C, D, E, F, G, H)$, y el lugar correspondiente al Gimnasio Universitario (VIII). El actual Panteón de los Próceers perteneció a la Universidad hasta 1924, habiendo sido la tradicional Iglesia de San Carlos. Hoy es una pertenencia del Estado. Existe en la parte correspondiente al Archivo Central "Domingo Angulo" una escalera que conduce al coro de dicha Iglesia.

La fachada principal da a la Avenida "Nicolás de Piérola" (antes Inambari). La Planta baja tiene 3 puertas y 19 ventanas y la Planta alta tiene 22 ventanas.

Fachada de la calle Cotabambas: la Planta baja tiene 3 puertas, 2 ventanas grandes y 3 ventanas pequeñas. Y la planta alta tiene 6 ventanas.

Fachada del jirón Azángaro (antes calle del Noviciado): la Planta baja tiene 1 puerta y 7 ventanas. Y la Planta alta tiene 8 ventamas.

La presente descripción comienza por el patio de Derecho y Ciencias Económicas y termina en el Gimnasio. Cada Claustro y cada Corredor posee: a) planta baja y b)planta alta. Cada uno se describe pariiendo de la pared básica, a la que por convención llamamos pl, y se la escoge orientándose hacia la puerta principal, es decir, en dirección Norte. Luego se sigue con la pared del lado derecho, a la que se denomina $p 2$, se continuaiconila t 3 copuesta la (la incial) y finalmente se concluye con la $p 4$ (opuesta a da p2) melli Converson

\section{I}

\section{CLAUSTRO DE LA FACULTAD DE CIENCIASS ECONOMICAS Y DE DERECHO.-}

Históricamente, durante la época del Convictorio de San Carlos, este Claustro fué llamado Patio de los Externos o de los Capistas o de los Manteístas o "de los Machos" y también Patio "de los Maestros". La puerta principal de la Universidad da acceso a este Claustro, en cuyo vestíbula existe una reja de hierro. Posee tres pasadizos, una pila en el centro, cuatro jardines con sendas palmeras y 27 columnas en la planta baja y 28 en la planta alta.

\section{Planta baja}

P1.-Aula No 1 de la Fac. de Ciencias Económicas y Comerciales. Administración.- Pasadizo o Vestíbulo A.- Seminario de la Fac. de Ciencias Económicas y Comerciales. 
NOTA.-El Pasadizo o Vestíbulo A consta de lo siguiente: Pl puerta principal de la Universidad y tablero central de la instalación eléctrica; P2 pared llana; P3 reja de hierro; y P4 pared llana.

P2.-- Sminario de la Fac. de Ciencias E. y C. (continuación).- Pasadizo B.- Biblioteca Central (puerta principal). - Decanato y Secretaría de la Fac. de Ciencias E. y C.

NOTA.-El pasadizo B consta de lo siguiente: Pl servicios higiénicos y depósito, y escalera hacia la planta alta, que al llegar a su parte media se bifurca en dos ramales. En la parte superior de la pared está ubicado el cuadro del dominico Maestro Fray Tomás de San Martín, quien obtuvo de la Reina doña Juana y del Emperador Carlos V la real cédula de fundación el 12 de Mayo de 1551.

P3.--Dos ventanas del Decanato de la Fac. de Ciencias E. Y C.-Pasadizo C.- Ventana y puerta lateral del salón de Actos de la Fac. de Ciencias E. y C.

NOTA.-El Pasadizo C, consta de lo siguiente: P2 puerta lateral de la Fac. de Ciencias E. y C.; P4 puerta principal del salón de Actos de la Fac. de Ciencias E. y C.- En el centro se encuentra el busto del Dr. Javier Prado y Ugarteche, que fué Decano de la Fac. de Letras y Rector de la Universidad.

P4. -Depósito de la Portería. - Aula No 3 de la Fac. de Ciencias E. y C. -Oficina dela Sección Jurídica, devar Sección Fincas y Oficina de Asistencia Social.

\section{Planta alta}

P1.- Rectorado (cinco ventanas externas).- Secretaría General( tres ventanas externas).

P2.- Aula del V año de la Fac. de Derecho.-- Pasadizo.- Aula No 1 de la Fac. de Derecho.-- Decanato y Secretaría de la Fac. de Derecho.

NOTA.-El Pasadizo consta de lo siguiente: PI lugar donde se halla colocado el retrato de Fray Tomás de San Martín; P2 puerta lateral de la Secretaría General; P3 puerta de la Secretaría de la Fac. de Derecho y pared llana, donde se encuentra una placa de los estudiantes del Chil colocada en 1938, y otra de la Universidad de Córdova (Ärgentina) colocada en 1944.

P3.- Salón de Actos de la Fac. de Derecho.- Seminario de la Fac. de Derecho.- Aula No 2 de la Fac. de Derecho. 
P4.- Arula № 3 de la F'ac. de Derecho.- Archivo Central "Domingo Angulo".

NOTA.-Existe en esta parte un trozo de pared perteneciente al Rectorado que tiene una ventana externa. Antiguamente esta era la habitación donde vivía el Rector. Hasta 1857 en que se abrió la calle Inambari, la ventana baja que hoy pertenece al aula $N^{\circ} 1$ de la Fac. de Ciencias E. y C. era la puerta principal del Convictorio de San Carlos, a donde más tarde pasó la Universidad de su antíguo local de la Plaza Inquisición.

\section{II}

CLAUSTRO DE LA FACULTAD DE LETRASS Y DE EDUCACION.--

Históricamente, este claustro fué denominado Patio de los Naranjos.

- Tiene cuatro pasadizos de aoceso, una pila al centro, corredores con 32 columnas, cuatro jardines con sendos naranjos y varias palmeras.

\section{Planta baja}

P1.- Dos ventanas laterales del salón de Arctos de la Fac. de Ciencias Económicas y Comerciales. Pasadizo C (anteriormente descrito).

P2.- Pasadizo D. - Aula No 7 de la Fac. de Letras. - Tres ventanas y una puerta laterap del salón de Actos de láfac. de Letras. - Pasadizo E.

NOTA.-El Pasadizo D contiene lo siguiente: Pl pared llana; P3 pequeña puerta lateral del aula No 7 de la Fac. de Letras. - El Pasadizo E contiene lo siquiente : Pl puerta principal del salón de Grados de la Fac. de Letras (atniqua Capilla de Nuestra Sra. de Loreto); P3 puerta de la Secretaría de la Facultad de Letras.

P3.- Puerta del Decanato de la Facultad de Letras.- Dos ventanas laterales del salón de Catedráticos de la Fac. de Letras.- Secretaría de la Sección de Cultura General (ex-Colegio Universitario).- Aulas Nos. 3 y 4 de la Fac. de Letras.

P4.- Aula No 5 de la Fac. de Letras.-Gabinete de Criminología de la Fac. de Derecho. - Pasadizo F.- Aula No 6 de la Fac. de Letras.- Antigua puerta que comunica con el Panteón de los Próceres. NOTA.-El Pasadizo F consta de lo siguiente: P3 servicios higiénicos y Depósito del Conserie, escalera que conduce a la parte alta 
que en la mitad se bifurca en dos ramales. Existe una placa con la fecha de la fundación de la Fac. de Pedagogía; P4 ventana y puerta lateral que sale al jirón Azángora (antigua calle del Noviciado); Pl hornacina con el busto del Dr. Julio C. Te1lo, quien fué Director del Museo Arqueológico y Catedrático de la Fac. de Letras, hecho por el escultor don Victorio Macho.

\section{Planta alta}

Pl.- Ventanas del Seminario de Derecho.

P2.- Continuación del Seminairo de Derecho.- Seminario de la Fac. de Letras (Institutos de: Filosofía, Historia, Literatura y Departamento de Estudios Extranjeros).

P3.- Continuación del Seminario de la Fac. de Letras. - Instituto de Etnología.- Oficina y Aula de la Fac. de Educación.

P4.-- Aula de la Fac. de Educación.- Vestíbulo.- Decanato y Secretaría de la Fac. de Educación.

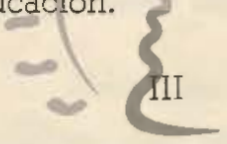

\section{CLAUSTRO DE LA FACULTAD DE LETRAS.}

Históricamente, este claustro se denominó Patio de los Jazmines. Se comunica con el primer claustro de Letras por los pasadizos D y E ya mencionados. En el centro existe una pila, cuatro jardines, los jazmines que la carcterizan y 27 columnas. En este claustra está ubicado el Salón General de Actos de la Universidad. Dos de los corredores ran sido habilitados para salón de Catalogación y Lectura, respectivamente, de la Biblioteca Central.

\section{Planta baja}

P1.- Ventanas laterales del Decanato de la Fac. de Ciencias E. y C.- Sala de Catalogación de la Biblioteca Central fconstruída en el corredor).

P2.- Puerta interior de la Biblioteca Central. - Salón General de la Universidad. - Sala de informes y lectura de la Biblioteca Central (construida en el corredor).- Pequeña escalera interior.

P3.- Servicios higiénicos.- Aulas I y II de la Fac. de Letras.Seminario de la Fac. de Letras. 
P4.- Pasadizo E.- Cinco ventanas y una puerta lateral.- PasadiZO D.

\section{IV}

CLAUSTRO DE LA FACULTAD DE CIENCIAS.-

Históricamente este claustro fué conocido con el nombre de Patio de Chicos. Tiene dos pasadizos de acceso y una puerta principal que da al Parque Universitario.- Al centro existe una pila y cuatro jardines, veinte columnas y una escalera doble, que a la mitad de su recorrido converge y lleva a los altos.

\section{Plantã baja}

Pl._ Puerta (Parque Universitario).

P2.- Salón de Mineralogía (construído en el corredor). - Escuela de Geología.- Pasadizo G.

NOTA.-El pasadizo G consta de lo siguiente: P1 pared llana; P3 puerta lateral de la Biblioteca Central (clausurada).

P3.-Cinco ventanas laterales de la Biblioteca Central.

P4.- Pasadizo B.-- Servicios higiénicos.- Anexo del Seminario de Ciencias Económicas (construído en el corredor). "Jorge Puccinelli Converso"

Planta alta

- P1.- Ventanas de la Secretaría General.

P2.- Seminario de Ciencias.- Decanato y Secretaría de la Facultad de Ciencias.

P3.- Aula N? 4 de la Fac. de Ciencias.- Sala anexa (construída en el corredor ypequeña puerta de comunicación con el corredor alto de la Fac. de Derecho).

P4.- Ventanas de la Secretaría General.

$\mathrm{V}$

CORREDOR DE LA FACULTAD DE QUIMICA.-

Este corredor se comunica con los otros Claustros por medio de los pasadizos G y $\mathrm{H}$. 


\section{Planta baja}

P1. - Salón de Ciencias.

P2.- Dos aulas de la Fac. de Química. - Aula de la Fac. de Ciencias (puerta de acceso a los altos'.- Decanato y Secretaría de la Fac. de Quírsica.- Pasadizo H.

NOTA.-El Pasadizo $\mathrm{H}$ consta de lo siquiente: Pl y P3 paredes llanas.

P3.- Aula de la Fac. de Química.

P4.-- Ventana de la Biblioteca Central. -Pasadizo G.- Ventanas de la Escuela de Geología.

\section{Planta alta}

P1.- Depósito de la Fac. de Ciencias.

F2. - Aula do la Fac. de Ciencias.

F3.- Sin construír.

F4.- Vetnanas de la Fac. de Ciencias.

\section{VI}

\section{CORPEIOR DE LA FACULTAD DE CIENCIAS.-}

Es un largo Corredor coni runal puerta queo da al Parque Universitario y una reja de hierro, que hace de puerta interior y la divide.

\section{Planta baja}

P1.- Puerta. (Parque Universitario).

P2.-Salón de Biología.- Salón de Geografía Física. -Dos ventanas laterales.- Salón de Geología y Paleontología.-- Gabinete de Física.

P4.-Salón de Química Orgánica.- Salón de Química Industrial.Pasadizo H.- Cinco ventanas de la Fac. de Química.- Conserjería de la Fac. de Química.- Escalera a la Tescrería.- Depósito de Química de la Facultad de Ciencias.

\section{Planta alta}

Pl.- Tesorería y Servicios médicos. 
P2.- Tesorería (continuación).-- Seccí́n sin construir.

P4.- Sección sin construír.-. Oficinas de la Tesorería.

VII

CLAUSTRO DE LA FACULTAD DE CIENCIAS Y DE QUIMICA.-

Este Claustro ilene al centro una pila, cautro pequeños jardines y sus corredores están en su casi tolalidad invadidos por construcciones complementarias.

\section{Planta baja}

Pl.- Anexo al laboratorio de Química.

P2.- Depósitos de máquinas ce la Fac. de Químíca. - Laboratorio de Química.- Salón de Física (Facultad de Ciencias).

p3.- Salón de Dibujo (Facultad de Giencias).- Depósito de máquinas de la Fac. de Química.- Salón de Dibujo de la Fac. de Ciencias.- Laboratorio de la Fac. de Clencias.

P4.- Laboratorio de la Fac. de Ciencias. NOTA.-Parte alta, sin construír.

\section{Bibliotecade Letras GIMNASIO UNIVERSSPIARAOLCCInelli Converson}

Esta dependencia de San Marcos tiene una Administración, Departamento de casilleros, duchas, piscina, cancha de Basket-Ball y el Gimnasio propiamente dicho.

\section{Planta baja}

P1.- Administración.- Ropero-- Duchas.

p2.- Puerta principal (calle Cotabambas).

P3.- Oficinas y gimnasio.

P4.- Piscina.

NOTA.-Al comienzo de esta calle existen dos puertas que pertenecen a la Tesorería de la Universidad. La planta alta, sin construír.

D. $V$. 


\section{DESCRIPCION DE LA CAPILLA DE NUESTRA SEÑORA DE LORETO, HOY SALION DE ACTUACIONES DE LA FACULTAD DE LETRAS DE LA UNIVERSIDAD NACIONAL MAYOR DE SAN MARCOS por Gred Ibscher}

Con fecha 4 de Octubre de 1886, el Decano de la Facultad de de Letras de la Universidad Nacional Mayor de San Marcos remitió una solicitud (1) al Rectcr de la Universidad, pidiendo que fuese cedida a dicha Facultad, para sus actuaciones públicas, "la antigua Capilla del Convictorio"... que "estaba dedicada al Culto, en el tiempo en que había internado en el Convictorio, lo cual ha desaparecido". Y describiendo el estado en que se veía entonces esta capilla, continúa: "En el día se encuentra enteramente desmamtelada como lugar de Oración. Los vasos sagrados, Custodia ,Tiara de la Virgen demás alhajas y los paramentos del Altar y omamentos de los Sacerdotes, no existen, a consecuencia de la guerra y de la ocupación chilena. Solo hay en ella un pequeño altar, con el busto de la Virgen de Loreto... La Capilla está cerrada y si así continúa, su deterioro es seguro, lo cual se salvará integrándola a la Facultad... que cuidará de mantenerla a su costo, en buen estado, Y con la decencia que requiere el noble fin para que la demanda". Dicha solicitud fué respaldada por un informe que presentaron, en conjunto medio año después', los Decanos de las Facultades de Jurisprudencia, Ciencias y Ciehciás Polítcias y Administrativas. Existía porontonces el problema de obtener de la Facultad de Letras un local en los altos que ésta compartiera con la. Facultad de Jurisprudencia, motivo por el cual todas se pusieron de acuerdo con tan feliz propuesta.

Al parecer tenían que pasar aún varios años antes de que se cumpliera el deseo de reingresar a la vida del claustro un recinto tan bello y venerable, que había caido en el más lamentable olvido y descuido, después de haber servido primero a los novicios Jesuitas de San Antonio de Abad y luego a los alumnos del Convictorio de San Carlos como lugar del culto y de oración. Encuéntrase tan sólo en el "Presupuesto de los gastos que deben hacerse en la Facultad" (de Letras) del año 1894 una partida de 500 soles para "Obras de albañilería, carpintería, pintura, vidrios, etc. en la Capilla y Sacristía, para convertir la primera en Salón de Actuaciones, y ésta en la Sala de espera". (2).

(1) Archivo T. 22, año 1886, Vol. 33. Estante III p. 445 ss.

(2' Archivo T. 30, año 1894, Vol.41. Est. IV p. 151. 
¿Cuáles son los trabajos de restauración y transformación que prácticamente se thicieron en esa fecha y que se cubrieron con la dicha suma?. Desgracidamente no conocemos, hasta el momento, ningún otro documento fuera de los mencionados de 1886 y 1894 respectivamente, que ayudaría a responder en concreto dicha pregunta.

Observando y estudiando la situación actual del lugar, se impone con urgencia la idea de buscar la forma originaria o sea la más antigua de la Capilla. La Proyección horizontal adjunta (3), la que incluía forzosamente partes adaycentes al Salón (a saber hasta la entrada de la actual Secretaría de la Facultad de Letras), da en cierto sentido la respuesta deseada, pero agudiza al mismo tímpo el problema existente en cuanto a las fechas y los resultados de las obras restauratorias practicadas aquí.

I.-CARACTER ARQUITECTONICO GENERAL Y LAS MODIFICACIONES POSTERIORES EN LA CONSTRUCCION.-

Quien examina detenidamente la capilla, se ve frente a los siguien. tes datos:

1) El local, cuya planta representa un sencillo rectángulo, sufrió en la parte de âtrás un acortamiento de su antes considerable extensión longitudinal; la actual pared de fondo, que ni por su calidad ni por el espesor puede compararse con las paredes laterales y la pared del altar, vino a destruir, enf-forma inexcusable, pinturas de la bóveda, cuya existencia se aprecian aún medlante débiles indieios. También muy grosero, nos parece el Jmóa cancque equíísel formó el ángulo de cada lado, mediante dos pilastras, las que habiendo sido vecinas a la misma distancia de las otras, antes nunca se tocaron tan de cerca, perdiendo la dignidad de su apariencia; hay además una diferencia en la calidad de la madera y el dorado ce las pilastras que flanquean la puerta de salida, caracterizándose éstas, frente a las otras de la Sala, como imitación barata, y de hechura de más reciente.

Obviamente debe considerarse como la antigua pared de fondo aquel muro que pertenece hoy a la Secretaría de la Facultad de Letras, no solamente porque sea idśntico en espesor y calidad a las demás de la capilla, sino porque las mismas medidas lo indican así. Los campos marcados con C y D en el plano, limitados por el muro de la Secretaría, pertenecían a la capilla y fueron sacrificados alguna vez, queriéndose ganar un tránsito, que hoy en esa parte existe.

(3) véanse también para lo siguiente. Planoz de la Capilla, Ilustración 1-2, que se deben a la colaboración del Sr. Arquiteclo T. Cron. 


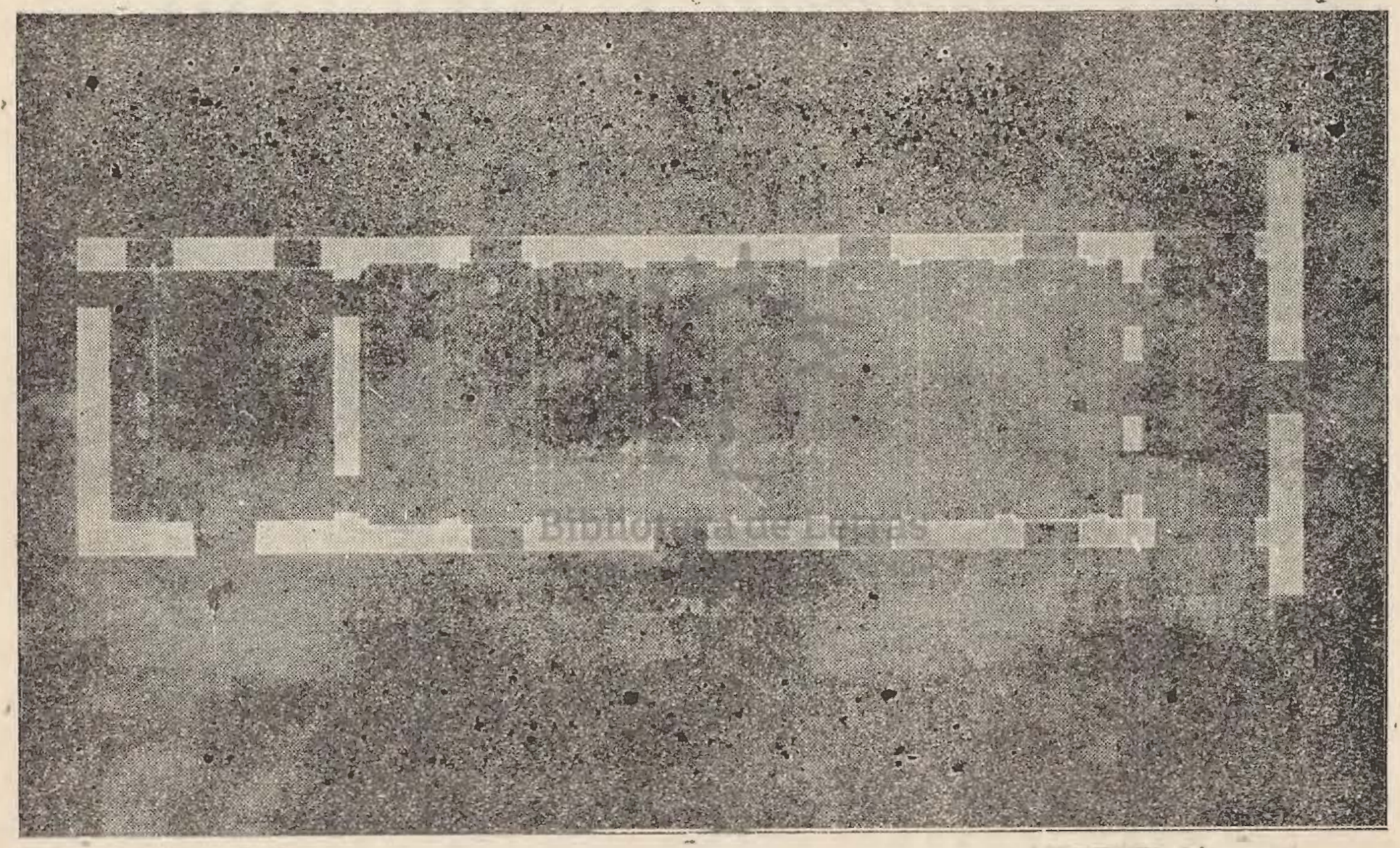

Proyección horizontal do la Capilila de Nuestra Señora de Loreto. 


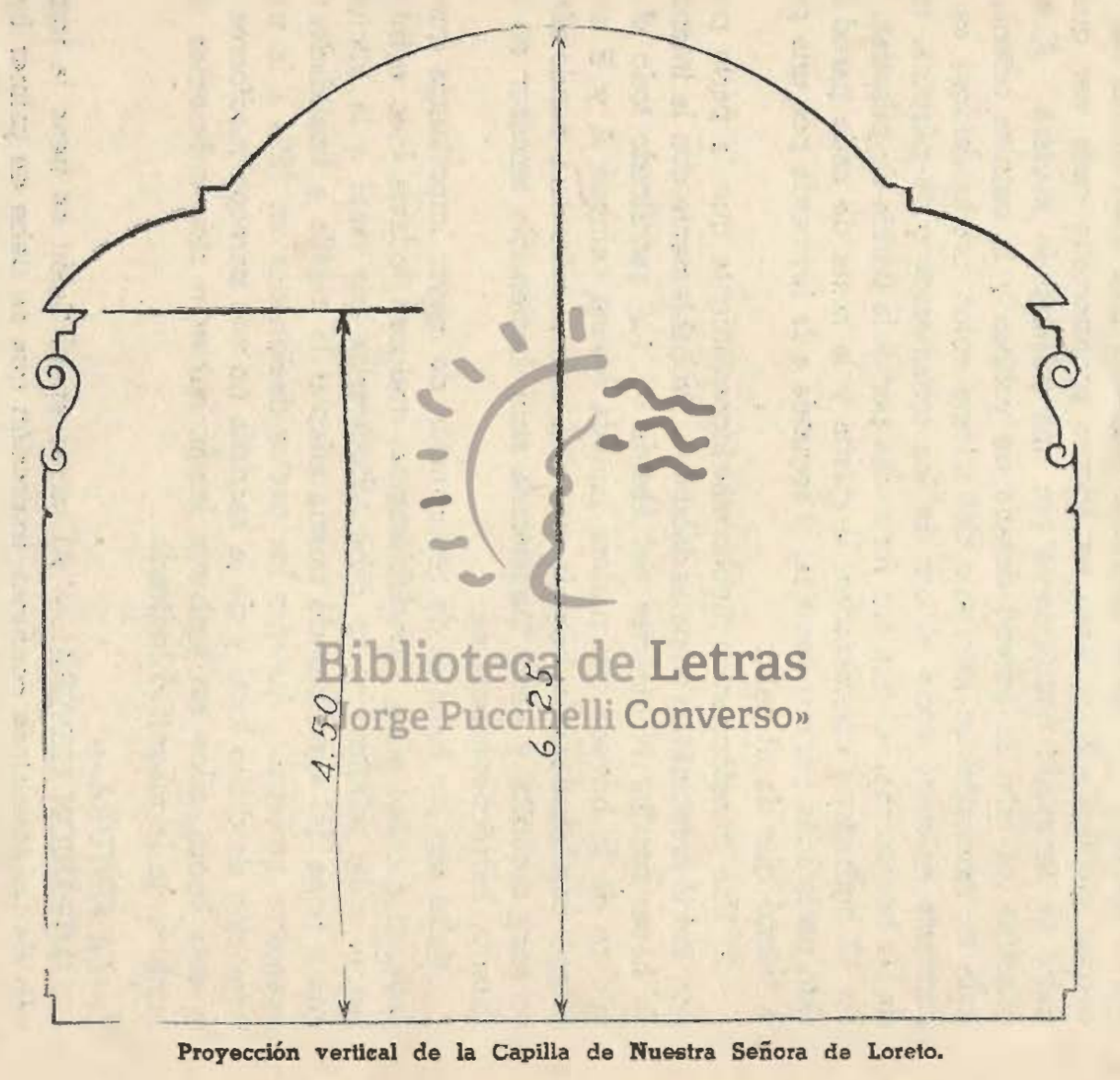


2) La capilla se cierra arriba por un techo abovedado, forrado en madera. Esta bóveda, en su parte culminante ligeramente achatada, se divide, por la forma de su arco refractario (véase proyección vertical adjunta) en tres segmentos: el segmento ancho central y los segmentos inferiores laterales. El techo descansa sobre, o más bien detrás de, una cornisa dentículada, saliente en ángulo pronunciado cada vez que el inuro os reforzado ficticiamente por una pilastra de madera. A estas pilastras les falta su adorno dorado de volutas y la cornisa ostenta en toda su extensión un astrágalo del mismo color, praduciéndose así un contraste solemne entre el oro de los ornamentos y la púrpura, color de las hornacinas, las que son formadas por cada pareja de pilastras. De las 12 hornacinas conservadas, la cuarta y la sexta de cada pared han sido perforadas por una ventana, la segunda a la izquierda por una puerta lateral que da al patio.

3) Una transformación mucho más inconveniente que la parte posterior, sufrió el recinto en su parte delantera. Probablemente con la intención de hacer resaltar el carácter del b́bside (4), fué sacrificado todo el comienzo de la bóveda de madera pintada tvéase campos A y B en el piano), cambiándose la bóveda por una arista, estructura seudo-gótica, no muy orgánica y hasta inadecuada aquí, haciéndola terminar en una linterna barroco-renacentista.

Tales son los trabaios de restauración det mayor importancia que se lievaron a cabo; ellossrindudablemente, traducen ctodavía celo e interés por el culto relígioso y no cabe adjudicarios por tanto a la iníciatíva que a fines del siglo pasado quería adaptar la capilla a finalidades enteramente profanas. Auncue los gastos designados en 1894 a la transformacićn de dicho local y de la sacristía no nos parecen mediocres para esta época, ellos sin embargo jamás hubieron sido suficientes para cambios de la magnitud indicada.

\section{II.- LA PINTURA.--}

IMPRESTON GENERAL.- Al entrar en el Salón se tiene la impresión de un armonioso conjunto, impresión que se debe en primer lugar a ia pirtura. Esta, por lo tanto, parece ser meramente decorativa. Se nota la tendencia, muy peculiar a los estilos de los siglos XVII y XVIII, de sustituir por medio de la pintura y de un dibujo plástico otras artes por ejempio, las de las diversas ramas de la escultura, ejecutadas on materiales de más peso y de más procio. También las filas de las san.

(4) ¿Con el migmo abjeto igual destino tué creads la estrada de madera? 
tas y santos, que cubren en ambos lados el segmento inferior de la bóveda, se ofrecen a primera vista ante los ojos como una especie de frisos decorativos, y sólo al contemplar los cuadros uno a uno, se descubre su común carácter narrativo. Pero, con toda la admiración que tributamos al pintor desconocido, autor de ese techo, haremos algunos reparos. Si la ornamentación revela buena técnica, si se combina en ella fantasía y un gusto refinado, el artista para retratar la figura humana, carecía de suficiente habilidad y de conocimientos anatómicos. En la expresión de las caras, su lenguaje es algo monótono. Los doce rostros de santos se ejecutaron a base de moldes modestos, convencionales; en las seis mujeres santas vemos una variación de sólo dos tipos; algunas caras, como la de Santo Tomás, se alejan ostensiblemente del modelo primitivo. Todas las figuras muestran no tener verdadera dimensión plástica.

Tal crítica no puede menguar el legítimo mérito de la obra, que consiste en que se ha creado aquí un ambiente a la vez digno y sereno. Es sorprendentemente fácil familiarizarse con el lugar, que une a su carácter solemne, una deliciosa intimidad. Desaparecen los errores en el detalle, al paso que el ritmo alegre de la decoración se nos transmite como un estado de euforía y las santas figuras nos invitan a participar en sus placeres contemplativos. Sorprendemos a unos en actitud meditâbunda, a otros escuchando la voz de la divina inspiración, estando a punto de escribir lo que than oido; las santas monjas, en pleno arrobamiento, saborean goces sobrehumanos o reciben revelaciones místicas. Surge de repente el verdaderoctena de toda esta" serie de cuadros laterales de la bóveda: es el triunfo del espíritu humano, que se ha entregado a Dios - fuente de toda Sabiduría- y que recibe, en recompensa, iluminaciones sobrenaturales. Este tema se impone de tal manera, oue algunos visitantes de la Capilla, ignorando la historia del local, y no preocupándose por las ilustraciones específicamente eclesiásticas, la toman desde un principio por una legítima aula académica, a la que adhiere, desde luego, un fuerte sabor a su pasado escolástico-medieval, cuando la Filosofía se consideró como "Ancilla Theologiae", sirviente de la Teología.

Para poder juzgar la obra en su verdadero valor, y para clasificarla en cuanto a su estilo, hay que conocer e interpretar primero la intención del mismo artista.

SIGNIFICADO DE LA OBRA.- Tenemos como término post quem de la creación el año del terremoto 1746, y sabemos que la Capilla, de acuerdo con su ubicación y capacidad, era una especie de Oratorio o, 
si se quiere, una pequeña iglesia doméstica. Llevaba el título de Nuestra Señora de Loreto, sea en honor al busto de la Virgen de: ese nombre, que adomaba el altar, o sea porque los Padres Jesuitas —adictos a la veneración de esa reliquia - querían realizar en dicho recinto una imitación de la así llamada "Santa Casa de Loreto". Se ha conservado una proyección horizontal con las correspondientes medidas (5) de una capilla de esa índole. Pero aparte del hecho que los números que en el viejo plano indican largo, ancho y altura (atenióndonos' a las medidas esenciales), no guardan proporción o semejanza alguna con ese nuestro local, faltan además todos los indicios posible para el acomodamiento de los obligatorios requisitos del Sagrado hogar, como la "alacenilla" y la chimenea".

Sirvió nuestra capilla al propósito de congregar la comunidad de novicios de la Compañía y más tarde al alumnado del Convictorio de San Carlos en sus diarios ejercicios relláiosos, y es la oración y meditación que el artista con su imaginación quería favorecer especialmente. Acoge a quienes entran - cerrando la puerta al mundo exterior- un verdadero mundo ficticio, toda una naturaleza estilizada, en recompensa de lo que se ha abandonado en el mundo de afuera. Pues no son las maravilias de la naturaleza en sí las que alejan y distraen el alma de su intención de reunirse con Dios, sino que por el contrario, es la misma naturaleza el medio por el cual el hombre sube y se acerca a su Creador. De ahí se expliç̧êl-afáp del piniore eñ reproducir, con sus propios medios, un aspecto de la más viva y fresca naturaleza. Dicha tendencia nos parece como un moviniento inverso al que se declara en las fachadas churriguerescas de muchos templos limeños del mismo tiempo, que representan verdaderas transposiciones de sutiles decorados del interior hacia la luz del día. Aquí, por el contrario, se han traído selectos motivos de una fecunda naturaleza hacia adentro, para regocijo de los que se dedican a la contemplación. Nos hallamos como

(5) Véase: "Quenta y medida de la Sa. Capilla de Loreto", Ilustración 3. Las medidas, exiraña acumulación de varas, tercias, cuartas, sesmas, dedos - se explican en su forma, que nos parece caprichosa, por la preferencia de determinados números, que tenían su valor como símbolos sagrados. Si reducimos al sistema métrico-decimal lo que aquí mismo se indica para a) el largo de una Sa. Capilla de Loreto, se abtiene $9.27 \mathrm{~m}$. b) el ancho es de $4.22 \mathrm{~m}$. c) el alto hasta el almizate llega a $5.23 \mathrm{~m}$. Estas medidas, comparadas con las de nuestro local - véanse Ilustraciones 1-2 - de inmediato dan a conocer, que son completamente ajenas las unas de las otras. 


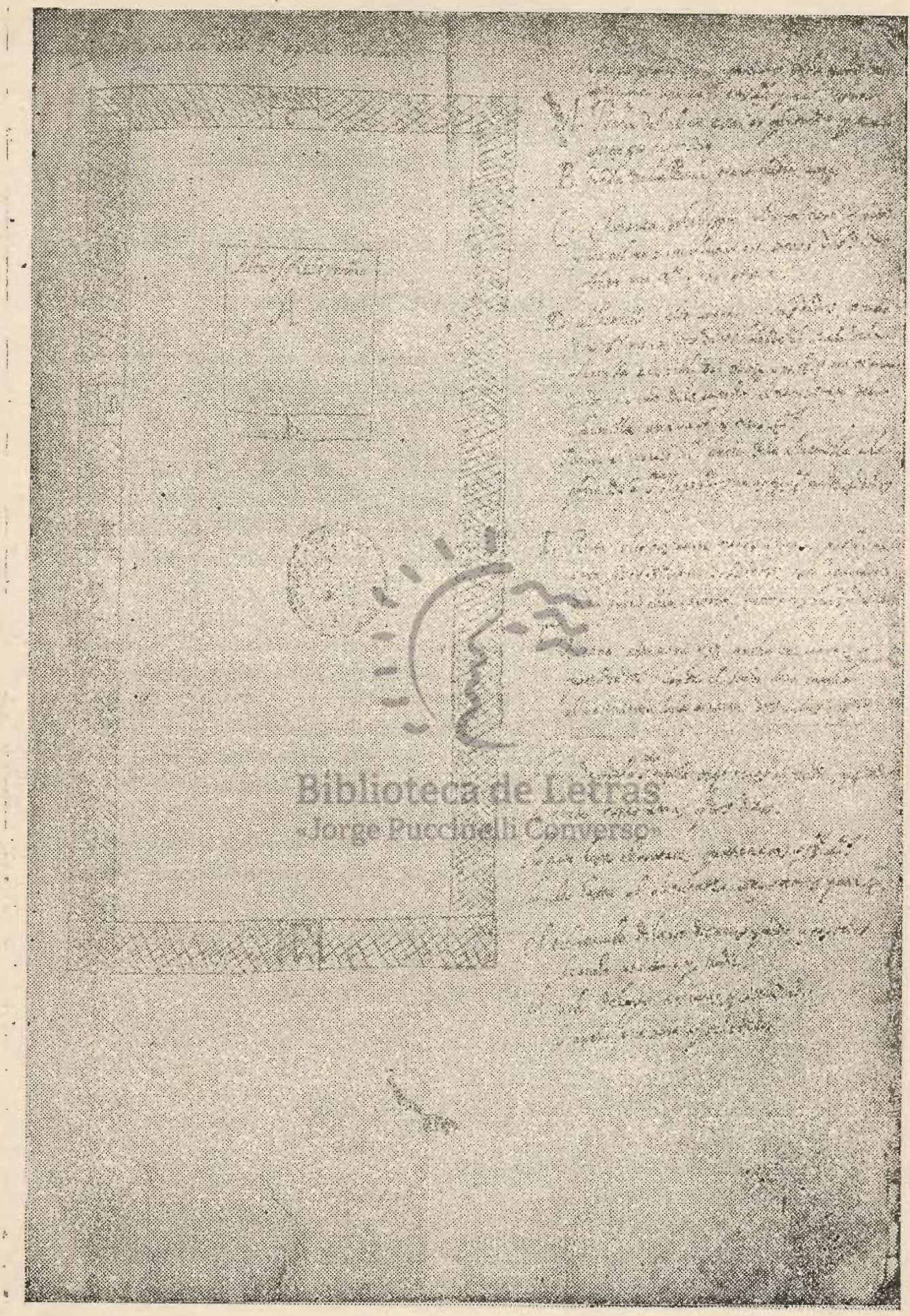


Quenta, y medida de la Sa. Capilla de Loreto-

La peana y altar están apartados de la pared de la chimenea una vara tres 4 ta. $Y$ un sesma.

A. Peana del altar esta en quadrado, y tiene siette pies y medio.

B. Grada de la Peana tiene media vara.

C. Chimenea de la Virgen alto una vara y media y una ochava: ancho una vara menos dos dodos fondo una $3^{\alpha}$ y una sesma.

D. Alacenilla. alto una vara $y$ tres dedos, ancho dos $3^{\text {as }}$. menos dos dodos, dende (sic) el suelo de la alacenilla a la tabla del medio una $3^{a}$. y una ochava dende el suelo de la capilla al nacimiento dela alacenilla una vara $y$ tres 4 tas.

Dende el remate de $h$ ancho de la alācenilla a la pared de la Sma. Virgen dos varas tres 4 tas. menos 4 dedos.

E. Puerta alto 3 varas menos sesma, ancho una vara, y dos 3as. menos dos dedos: esta apartada de la pared de la Bibrentaria quatro daras una $3^{3 a}$ y dos dedos.

"Forventana Caltonvara $\mathrm{y}$ (3) Vancho una vara y quatro dedos, dende el suelo de la capilla al nacimiento de la ventana dos varas y $3^{a}$.

Lo largo de toda la $S^{\text {ta }}$. Capilla onze varas y media, y 4 dedos

lo ancho cinco varas $\mathrm{y}$ dos dedos.

lo alto hasta el central quatro varas y $3^{e .8}$. $t^{\text {ns }}$.

lo alto hasta el almicate syes varas y una $t^{2}$.

el tabernaculo de largo dos varas y media, y tres dedos

de ancho una vara y media.

el nicho de largo dos varas, y siete dedos

de ancho una vara $y$ ocho dedos.

NOTA:

En el reverso de la foja dice: "Medida de la Sta. Capilla de Loreto". 
debajo de un techo florido y tejido de hojas, ramas y guirnaldas, cuya sombra benéfica nos agrada especialmente en un día caluroso, cuando una luz dura y demasiado brillante hiere los ojos.

EL COLORIDO.- Es precisamente la calidad de los tonos, lo que ejerce un efecto de extraordinaria calma; ningún color es tan provocatico que traiga toda la atención sobre sí. - Hay un perfecto equilibrio aún entre los tonos más fuertes del rojo-púrpura —color eclesiásticoy el verde de la vegetación fértil. Ambos, el rojo y el verde, aparecen en una modalidad distinguida, digamos ligeramente apagada. Así se ven los colores del paisaje al terminarse un día de verano; aunque el sol se haya puesto ya, los objetos retienen aún algo del calor y de la luz que han bebido. Entre el contrapunto del rojo y verde percibimos toda una gama de matices que se derivan de dichos tonos predominantes: el rosado, rojo sangre, el morado un gris claro, gris color sombra, gris marrón, gris humo, para enumerar algunos pocos. ¿Le faltó al pintor en su paleta el azul?. Extrañamos pues en el manto de la Virgen (Campo III centro) el tradicional color celeste; las nubes aparecen en gris plateado o en un color de un gris grafito, muy amenazante. Donde únicamente se ostenta una franca tonalidad azul aguamarina, es en la esfera sostenida por la mono del Creador Todopoderoso. Mencionamos en último lugar el oro, porque no pertenece a dicha escala cromática. De acuerdo con su carácter hlerátioo, Cdesempeña dos funciones: separa y subraya. Encuadrandol los medaliones ('Campos ecentrales I-VI) de la bóveda y los cuadros de los santos (Serie lateral inferior de ambos lodos) el oro, aplicado con trazo firme, siguiendo toda clase de lineas geométricas, aparta el contenido sagrado de todo el juego artístico-profano circundante; cuando aparece dentro de un cuadro en toques ligeros, es para dar más relieve a las cosas celestiales y sobrenaturales.

ESTILO.- Si se quiere encontrar efectos cromáticos parecidos a los que percibimos en ese techo, hay que buscarlos acaso en las decoraciones parietales de las villas romanas (compárese p. ej. el estilo decorativo de las casas pompeyanas); vemos enriquecidos estos mismos colores y motivos, dotados de una cada vez más rica naturalidad, en las cúpulas de algunas basílicas romanas de la primera edad cristiana (bien conservado y en este sentido ejemplar: los mosaicos de Santa Costanza, Roma, s. IV). Para ir menos lejos, bajo los Borbones renace en España este mismo gusto de decorar los interiores con ricos motivos de fresca y graciosa naturaleza, entremezclados con arabescos, que fingen ser tallados en madera o esculpidos en piedra, estilo traído de 
Francia y empleado en los palacetes, retiros y casas de campo, construídos para el descanso de aquellos Reyes.

No hay, pues, en la capilla influencia del Churrigueresco, sino un pronunciado ascendiente del Rococó. Así hay que entender las guirnalas, racimos de uvas, manzanitas frescas, unido todo esto a los arabescos de la más variada índole, con largas cintas rosadas, que pasan por las manos de desproporcionados angelitos; vemos ninfas-cariátides con los pechos desnudos; caretas; que nos recuerdan los abre-puertas de metal, colgando de puertas antiguas; hay cabecitas de ángeles aladas, conchas, volutas, consolas y cornisas adornadas de bajo-relieves enseñando elegantes líneas clásicas. Escasamente se repite un motivo en tan ubérrima variedad. Todo esto se hizo para contribuír al loor divino, y no perjudican en ese alegre conjunto, que es moderado por un sobrio gusto y finos sentimientos religiosos, algunos elementos de un inocente paganismo, tan propios a los estilos de los siglos XVIIXVIII. Esta riqueza ornamental no está recargada en ningún punto, razón por la cual es difícil sustraerse al encanto que proporciona este local hasta nuestros días. Sin embargo, diremos que el efecto estético no sirvió sino de pretexto, y que se consideró como un momento su bordinado en toda la obra. El pintor, a través del deleite estético, que ría transmitir una paz espiritual, para comenzar luego, él a hablar con mucho sosiego acerica de los misterios de la yida de la Virgen. Por esto, cuando los medios artísticos no le alcanzan para ser suficientemente claro, para especificar su mensaje o para contar todo un largo pasado, entonces el artista recorre ingenuamente a la palabra escrita, agregando unas que otras noticias en latín.

\section{TRADUCCION DE LAS LEYENDAS E INTERPRETACION DE LOS} CUADROS DEL TECHO.-

Tres cosas piden por separado nuestra atención:

A Las cintas o fajas de la bóveda, que - en número de siete-subdividen la parte ancha mediana del techo abovedado en B seis campos centrales (I-VI), y

C la porción del margen inferior en ambos lados, cubierta por cuadros de temas hagiográficas (Serie lateral la $-6 a ; 1 b-6 b$ )

Adoptamos, para evitar confusiones, en todo el curso del texto descriptivo los números 1 a $\mathrm{t}$ i $\mathrm{n}$ o $\mathrm{s}$ para designar la parte central de la bóveda, mientras las cifras a $r$ á b i g a $\mathrm{s}$ se refieren a la serie hagiográfica lateral. El índice alfabético a) significa siempre lado d e $\mathrm{r}$ e $\mathrm{cho}$, b) lado i z qu i e r d o (desde la posición de quien se 
encuentra con la frente dirigida hacia la antigua pared del altar, y c) quiere decir: centro.

\section{A}

Las fajas de la bóveda

Nacen de cada pareja de pilastras opuestas, exactamente aquí donde la cornisa saliente, en unión con su respectiva archivolta, marca el borde superior de la pilastra, fajas estrechas y de escaso relieve; éstas, siendo adaptadas al arco de la bóveda, dan lugar, en su segmento inferior, a cortas noticias biográficas, de las que van acompañadss solamente los cuadros: la - - $3 \mathrm{a}$ y $1 \mathrm{~b}-3 \mathrm{~b}$, - ocupándose el mismo espacio en los cuadros restantes con letras de una inscripción, de la que son portadores todas las fajas en su conjunto. Las letras - doradas mayúsculas latinas - fueron trazadas sobre pequeños discos' (o botones circulares), aplicados éstos de un modo que guardan la misma distancia entre sí.

Leyendo linea tras linea, fácilnente reconocemos un texto litúrgico contínuo (que en el Misal Romano aparece como el Graduale de la Misa del 8 de Diciembre, Fiesta de la Inmaculada Concepción). Los versos provienen mitad del Cantar de los Cantares, mitad del Libro de Judith. La linea inicial TOTA PUICHRA ha sido restablecida en letras negras por la mano del restaurador; habiéndose removido la faja que unía la primera pareja de pilastrast ne quedé sino la antigua pared del altar como sitio para fijar las palabras del comienzo Sigue luego ininterrumpido el texto hasta TU HONORIFICENCIA, línea escrita sobre la última faja existente hoy día. Reproducimos, sin embargo, en lo siguiente el texto íntegro, para dejar constancia aún en esta forma, de que la Capilla había sido mutilada, habiéndose eliminado una pareja de pilastras con su respectiva faja, en la que encontraron las palabras finales del verso. Dicha cinta suprimida siguió a aquellos cuadros laterales, cuyos restos quedan aún perceptibles; junto a ella desapareció un campo central y dos cuadros laterales - pérdida, que en el estado actual ni por huellas se traduce.

El texto que ofrecen las cintas con su traducción:

TOTA PULCHRA

ES MARIA

ET MACULA.

ORIGINALIS

Todo hermosa

eres tú, María

NON EST IN TE.

y la mancha

original

no hay en tí

(Con ligera modificación: Cant. 4, 7 - aplicado a la Virgen) 
TU GLORIA JERUSALEM

TU LAETITIA ISRAEL

TU HONORIFICENCIA

(POPULI NOSTRUI)
Tú, gloria de Jerusalén,

tú, alegría de Israel,

tú, el honor

(de nuestro pueblo).

(Judith, 15,10)

$B$

\section{Los seis campos centrales}

Los campos I-IV-VI ofrecen cada uno $\mathrm{t} \mathrm{r}$ e $\mathrm{s}$ situaciones simbólicas, alusiones a los diversos atributos místicos de la Virgen, sacados algunos del Antiguo Testamente, otras por ejemplo de la Letanía llamada la Lauretana (en honor de la Vírgen de Loreto), los campos II y IV sólo reproducen dos, mientras el campo III, representa a María rodeada de ángeles momentos antes de su coronación en el cielo.

\section{Primer campo}

Texto de las leyendasBiblioteca Traducción al Castellano

Ia-: Quasi Palma exaltata sum ellifrecí como la Palma de Gades in Cades

Ib-: Quasi Cipressus in Monte Como el Ciprés en el Monte Sión. Sión.

\section{Eclesiástico 24, 17-18}

IC-: Puteus aquarum viventium Pozo de las aguas vivas.

\section{Cant. 4, 15}

No por mero capricho cuatro angelitos de la decoración están empeñados en pasar, con vísible esfuerzo, largas cintas rosadas a través de los ojales de los tres medallones-cuadrosi, enlazándolos así exteriormente; pues el contenido alegórico de los medallones, a saber: Palma, Ciprés y Pozo-Cisterna, tienen que ver el uno con el otro. Entendiendo 
bien la insinuación hecha de parte del mismo pintor, no hemos de leer el significado de las tres imágenes cada uno aisladamente, sino que, al contrario, debemos contemplarlas como diferentes aspectos de un mismo tema:

El Ciprés, árbol de las tierras altas de pastoreo en Judá, y la Palma, meta fervientemente anhelada de los pastores-nómadas que se mueven de oasis en oasis con sus rebaños sedientos: ¿no deben acaso ambas plantas su existencia al agua, de una fuente-cisterna en cuya cercanía las afortunadas crecen, mientras les rodea un ambiente árido rocoso o sea arenoso? Y como el agua les proporciona un tronco esbelto de belleza soberbia y el color verde de una vitalidad incomparable en tales lugares, así la Virgen María, dotada de la gracia divina llegó a la belleza del alma y a una vitalidad espiritual sin par, siendo enderezada por encima de las criaturas, contaminadas con el pecado original.

Texto de las leyendas

\section{Segundo Campo}

IIa--: Templum Spiritus Sancti. Templo del Espíritu Santo.

IIb-: Hortus conclusus. Huerta cerrada.

Cant. 4, 12.

Los motivos de estebdámpoecontinúan tratandosel tema anterior. Confróntase aquí una imagen del Antiguo Testamento con una metáfora usada frecuentemente en el Nuevo. Vemos en el lado izquierdo un huerto de severa configuración geométrica, cercado por un alto seto vivo y cerrado por una puerta maciza. Un lugar tan resguardado debe ser un precioso escondite, un delicioso recinto de paz y de imperturbable sosiego, muy diferente de los lugares ruidosos a los que concurre todo el mundo para divertirse. Compárese con un sitio tal el casto seno de la Vírgen, que se convirtió, - mediante el poder del Espíritu Santo - en dígno albergue y templo viviente de la Deidad.

Tercer Campo

Texto de la leyenda: Regina Angelorum
Traducción al Castellano

Reina de los ángeles.

Letanía Lauretana 
El pintor, complicando su tarea, trata de crear, en una superficie netamente rectangular, la ficción de una cúpula de configuración circular. En su intento fracasa parcialmente, sobre todo donde quiere aparentar las dimensiones profundas del cielo, y en las figuras que compone en dichos planos; me refiero antes de todo a los ángeles desproporcionados que, baílando en derredor, abren a la Virgen el paso hacia la Trinidad; Padre e Hijo, accmodados en un espacio triangular formado de un fondo de nubes, le tienden a la fiutura Reina la corona celestial. Mucho mejor logrado es el grupo de los doce apóstoles (seis de cada lado), que el pintor compone en el plano bajo del lado derecho. Los que eran primero discípulos de Cristo y luego fieles compañeros de su Madre, acaban de enterrar el cuerpo de la Virgen, hecho de lo cual queda como testigo un lienzo blanco que sa asoma del sepulcro destapado. Ella, desprendiéndose del nivel terrestre y acercándose a las nubes y las estrellas, es empujada vigorosamente hacia arriba por los pequeños "espíritus" alados. En las caras varoniles de los doce hombres que quedaron atrás, se pinta sorpresa, profunda emoción y reflexión. Dispuestos a una fé devota, aceptan el acontecimiento sobrenatural, pero no todos sin discutirlo, como hace la figura extrema de la primera fila, rechazando el vecino, con sus rasgos típicos de un anciano San Pedro, toda posibilidad de dudas en un gesto enérgico de la mano; otro de los apóstoles parece asegurarse leyendo en las tradiciones escritas de sí la voluntad divina habia de cumplirse en realidad de aquella manera. El último tercio de espacio - al lado izquierdo - llena un grupo de ángeles musícantes, "Los que cantando y $90 \mathrm{cando}$ varios instrumentos o esparciendo flores, celebran el trascendental evento; creo que nos encanta en ellos menos su cualidad artística que la despreacupada e ingeniosa alegría que en sus actitudes demuestran.

\section{Cuarto Campo}

Texto de las leyendas

IVa-: Intravit Jesus in quondam (sic) Castellum

$\mathrm{IVb}$-: Turris Davidica

Letanía Lauretana.

Ivc-: Porta Celi

Letanía Lauretana.
Traducción al Castellano

Jesús entró en una foríaleza.

Torre de David.

Puerta del Cielo. 
No cabe duda que los motivos de este campo reanudan y amplifican la idea del campo II. Si en éste fué mencionado el lugar de la divina Concepción, se habla aquí especialmente del secreto de la Encarnación de Cristo y lo que ella significa para la generación humana. María, Madre de Dios, llega a ser Puerta, es decir intermediaria entre el cielo y la tierra. Dios, escogiendo a ella, que es de la estirpe Real de David, como madre, se incluyó a sí mismo en la descendencia genealógica de los hombres. En este sentido hemos de comprender la invocación metafórica: Torre de David. El motivo del lado opuesto - Cristo, que visita una fortaleza - repite y subraya lo que a su vez las guirnaldas frutales de la decoración expresan: el misterio de la maternidad sublime de María.

Texto de las leyendas $V$ :a-: Scala Jacob

$\mathrm{Vb}$-: Candelabrum cern (al) ibus

\section{Quinto Campo}

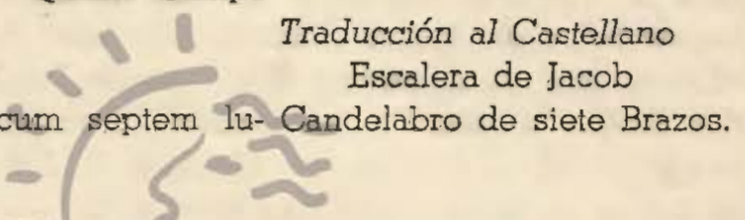

Sabemos que el Cándelabro de siete Brazos pertenecía al Santuario interior del Templo de Jehová. La Escalera de Jacob es aquella imagen de sueño, en la que el tercero de los Patriarcas vió subir y bajar ángoles, visión que, al despertarse él, le mueve a exclamar: 'No es otra cosa que la Casa de Dios, y esta es la Puerta del Cielo". Podemos relacionar también estosidos motivose ho menos que los anteriores, con la historia de la Salvación y el papel preponderante que María tuvo en ella. Como Madre de Dios, interviene en favor de la humanidad ayudándole a encaminarse hacia arriba, hacia la luz y la felicidad del paraíso.

\section{Sexto Campo}

Texto de las leyendas

VIa-: Civitas refugii

VIb-: Foederis Arca

VIc-: Corona esultacionis

Letanía Lauretana.
Traducción al Castellano

Ciudad de refugio

Arca de la Alianza

Corona de alegría.

Tanto el Arca que divide majestuosa y seguramente las olas oscuras de un diluvio hostil, como, del otro lado, la ciudad que al igual 
de una Jerusalén Celestial o "Ciudad de Dios", brinda refugio y protección, ambas imágenes simbolizan la Iglesia Militante, la que después de un tiempo de transición y de pruebas, se convertirá en Iglesia Triunfante, coronándose así la divina obra de la salvación, que comenzó en María. Una magnífica corona en forma de cofia, cuyo diente del centro remata en una cruz, se levanta sobre un cáliz lleno de frutas - alusión al fin triunfal.

\section{C}

Los cuadros laterales de la parte inferior del techo

No es posible entablar conexión temática entre los cuadros que cubren la superficie central y los que se extienden sobre el margen en ambos lados del techo. Figuran retratados (hablando solamente de los cuadros que se conservan íntegramente hasta hoy), primero los cuatro principales Doctores de la Iglesia del Occidente: San Jerónimo (n. alre dedor de 331 - m. 420); San Greporio (n. 540 - m. 604); San Ambrosio (n. 340 - m. 397); y San Agustino (n. 354 - m. 430). Les precedieron, con la mayor probabilidad los cuatro Evangelistas. Pero el lugar que hoy día ocupa San Juan; correspondía a San Marcos; pues sólo el Evangelio de San Marcos comienza con las palabras:

\section{Initium Evanjelif Jesu Christi Ca.TRAD.:- Principio del Evangelio Filij Dei "Jorge Puccindeljesucristo, SHijo de Dios.}

Preceden, como se ve, dichas palabras a un cuadro destruido del Evangelista. Así descuidó el pintor, encargado con la refacción de los cuadros suprimidos de la bóveda, también en el lado derecho la noticia que acompaña al retrato anterior, que no podía ser el de San Mateo, tal cual se halla hoy; porque son palabras de San Lucas 1,5 que leemos aquí, palabras inicilales del verdadero relato evangiélico hecho por S. Lucas:

Fuit in diebus Herodis Sacerdos quidam
TRAD.: Hubo en los días de Herodes un Sacerdote.

De modo que, si se enfrentaron como primera pareja de Evangelistas San Marcos y San Lucas, seguían a ellos, en orden invertido 
al de hoy, San Juan y San Mateo como más cercanos a la pared del altar, pared común entre la Capilla y Sacristía.- Estableciendo un re cuento total de los cuadros habidos, se obtienen:

cuatro Evangelistas

cuatro Doctores principales de la Iglesia Occidental

\section{Siguen:}

dos Doctores del siglo XIII, declarados posteriormente "principales", a saber el

franciscano S. Buenaventura (n. 1221 - m. 1274) y el domínico Santo Tomás (n. alrededor de 1225 - m. 1274). Obtenemos así un número de $d$ i e z santos varones. Se salvaron además los retratos de seis santas mujeres, todas notables por su erudición teológica y su misticismo. Dos entre ellas son especialmente conocidas por su intervención de hacer regresar la Sede Papal de Avignon a Roma, a saber: Santa Catalina de Sena y Santa Brígida de Suecia. Forma pareja Santa Magdalena de Pazzis, Carmelita de Florencia (n. 1566 - m. 1607) con la gran Teresa de Avila, reformadora del Carmel (n. 1515 - m. 1582); vemos a Santa Catalina de Boloña (n. 1413 - m. 1463), la que tomó el hábito de las Clarisas de la observancia de San Francisco de Asís, frente a Catalina de Sena hnil347 ot me1380).edomínica; termina, en el actual estado de cosas, la fila de santas mujeres con una pareja del Norte de Europa, a saber con: Brígida, la gran mística sueca (n. $1302-\mathrm{m}$. 1372) y Gertrudis, la docta teóloga germana (n. 1256 - m. 1302 ?).

Siguen, camo observamos, dos cuadros bruscamente cortados en su primera octava parte, cuyos restos no son suficientes para permitir conjeturas acerca de las figuras que representaban.

En el lado derecho se percibe sin dificultad una cabaña cubierta de paja que se destaca de un fondo verde-azul intenso y se deja apreciar tal vez la aparición de un crucifijo milagroso, de modo que - sin lugar a dudas - se trataba en ese cuadro, - por excepción esta vez, de una escena al aire libre, mientras todos los demás, fuera de la de San Jerónimo, enseñan el interior de una celda monástica; también los restos que apreciamos después del retrato de Sta. Gertrudis, enseñan con su mesa, tintero y estante de libros, un ámbiente de esta índole. Aquí quedaron aún dos últimas letras del título: L A. 
Para llegar al mismo número d i e z de cuadros de Santas como hay cuadros de Santos - de acuerdo con el principio de estricta simetría que se observa en toda la disposición de la Capilla - es de suponer que, fuera de la pareja de retratos semidestruidos, fueron eliminados dos cuadros más, de los que no quedan rastros - una hipótesis, que se respalda en varias observaciones demostradas anteriormente.

El comentario siguiente, a más de incluir una traducción de las leyendas escritas en latín al castellano, quiere proporcionar algunas indicaciones para facilitar la lectura y contemplación de esta serie de cuadros hagiográficos.

Si vemos los retratos $l a-3 a$ y $l b-3 b$ recargados de emblemas y otros detalles, - en el resto, al contrario, llama la atención cierta pobreza en la expresión del medio y convencionalidad en la reproducción.

El artista, autor de los cuadros, es - como ya una vez dijimos menos pintor que elocuente narrador, quien, antes de deleitar estéticamente, quiere enseñar, ofreciendo sus figuras en medio de detalles representativos para hacer presente al santo personaje en todo lo que atañe a su historia.

\section{Nota:}

Varios títulos y leyendas fueron renovados por una mano inexperta, que no supo restituis elb texto latino, reemplazándolo con más o menos fidelidad por palabras castellanas. Sin embargo será una cuestión para siempre insoluble, si p. ej. la noticia biográfica-única que existe entre los cuadros de mujeres santas, de Santa Catalina de Boloña, había sido escrita anteriormente en latín o más bien agregada posteriormente por el pintor encargado de la restauración. Preferimos imaginarnos que a ningún cuadro de la capilla faltaba su respectivo dato biográfico dentro - fuera del cuadro, habiendo sufrido por la intemperie y otras incle mencias del tiempo especialmente los textos de tal manera, que no era posible reconocer y restituirlos a su antigua forma. 
la-:

S. HIERONIMUS. DOCTOR EECLESIE (SIC).

(San Jerónimo, Doctor de la Iglesia)

- Leyenda a la derecha del cuadro -

S. Hiero / nymus, Eusebis / filius, St / ridone in / Dalma / tia Cons / tantio / Impera / tore / natus

TRAD.: San Jerónimo, hijo de Eusebio, nació en Estridón en Dalmacia, bajo el Emperador Constancio.

El que fué secretario y consejera del Papa Damaso I, a quien buscaron las grandes damas romanas para confesor, se había retirado, como en los días de su juventud, al desíerto que queda cerca a la Tierra Santa, dedicándose por entero al estudio de la Sagrada Escritura y a la fiel versión de la palabra divina. El capelo cardenalicio - recuerdo de los días de fama en Roma - cuelga ahora de las ramas de un árbol seco. No vale sino la fuerza del espíritu. "Galeatus" se lee debajo de un yelmo puesto sobre uno de los libros: vestido con un yelmo, es decir: con la armadura de un soldado de Dios, Jerónimo comparte con las fieras (león) la vida más dura posible, vida que extenuará con sus privaciones casi sobrehumanas su cuerpo hercúleo. Y tan convencido está de que así debe pasarse el siglo, que trata de atraer una vez más al antiguo compañero ermitaño Heliodoro (Epistola ad Heliodorum: Carta a Heliodoro) al desierto. Porque inmensa es la recompensa, El santo acaba de recibir en ese mismo momento, bajo tremendos efectos acústicos (campana - trueño - tempestad) un mensaje de su Dios: "Columnae cceli contremiscunt et pavent" - las columnnas del cielo se estremecen y tiemblan.

\section{$1 \mathrm{~b}-\mathrm{-}:$ \\ S. GREGORIUS. M. DOCTORE (siC) ECLESIE}

(San Gregorio Magno, Doctor de la Iglesia)

- Leyenda a la izquierda del cuadro -

S. Gregorius / Magnus Roma / nus, Pontifex / Maximus. Gordiani Senato / ris Filius, ad / mirabilia sc / ripsi (sic), que Cum / dictaret, 
Sae / pe Spiritus / S. Columbae / Specie in / eius capite / Visus est./

TRAD.: San Gregorio Magno, Romano, Sumo Sacerdote, Hijo de Gordiano el Senador; escribió obras admirables; mientras que las dictaba, el Espíritu Santo, bajo la figura de una paloma, fué a menudo visto sobre su cabeza.

Una nota suntuos'a $y$, en su manera, no menos patética que la que distingue el cuadro enfrente, caracteriza el ambiente del estudioso Papa; es el que, después de una carrera política fulminante, inició otra igualmen extraordinaria dentro de la Iglesia Romana, hasta que, aclamado por pueblo, senado y clero, - llegó al puesto más alto de dicha jerarquía. El béculo, insigne de la dignidad episcopal, la muceta cardenalicia que lleva puesta sobre una camisa de coro de ricos encajes, la cruz de tres brazos y finalmente la tiara, marcan las etapas de su vida eclesiástica. San Gregorio fué considerado como uno de los más inspirados y acertados teólogos: "Conscripsit sermonas rectissimos el veritate plenos". -- Escribió sermories plenos de rectitud y de verdad. Eclesiastes 12, 10. El pintor lo hace componer el Comentario "In Librum Regum" - sobre el libro de los Reyes, el cual está calificado hoy como escrito apócrifo.

$$
2 a--
$$

\section{S. AMBROSIUS. DOGTOR ECLESIAE}

\section{(Sam) Ambrosio, Dodtor de var Iglesia)}

- Leyenda a la derecha del cuadro -

S. Ambro / sius Epis / copus Me / diolanen / Sis, Ambro / sis Civis / Romani filius, Pat / re Galliae / Praefecto / natus est./

TRAD.: San Ambrosio, Obispo de Milán, hijo de Ambrosio, ciudadano Romano, nació, siendo el padre Prefecto de Galia.

El famoso Arzobispo de Milán (sus insignias: ínfulas, el báculo pastoral, la cruz de dos brazos, pectoral y estola de lana de cordero que lleva puesta) ejerció gran poder sobre las almas por medio de su palabra dulce, afable, elocuente. En este sentido hay que interpretar la colmena de abeias en el centro. Pero el mismo que convirtió a San Agustín, excomulgó en otra ocasión al Emperador Teodosio, porque supo usar a tiempo también el látigo, señal de su autoridad eclesiás- 
tica de juez imperturbable. Así S. Ámbrosio, el Cicerón cristiano, en la lucha contra la astucia del diablo-serpiente, que se cree Rey coronado de ese mundo, y está a punto de tragar a la pobre humanidad, se sirve de una arma de doble filo que es: dulzura y severidad. Pare ce que aún el cuerpo delgado del santo ensimismado participa en el árduo esfuerzo de la meditación: "Sunt quaedam difficilia intellectu"Hay cosas difíciles de comprender.

$$
\text { 2b-: }
$$

\section{S. AUGUSTINUS, DOCTORE (sic) ECLESIE}

(San Agustín, Doctor de la Iglesia)

- Leyenda a la izquierda del cuadro -..

S. Augus / tinus / Episcop / us Hippo / nensis / Eclesiae / lumen, et / Columen, / natione / Afer, Ta / gaste in Numidia / natus! /

TRAD.: San Agustín, Obispo de Hipona, lumbrera y columna de la Iglesia; Africano de origen, nació en Tagaste. Numidia.

Infulas y báculo caracterizan su ulterior dignidad eclesiástica de un Obispo de Hipona. Il El icorazónzen llamas, toue Saparece encima del pectoral, alude a su temperamento apasionado as su ardiente amor de Dios después de sus años intranquilos. Detrás de la silla en que el Santo se halla reclinado, surge el sol de la divina Sabiduría, mientras otrc círculo luminoso, que lleva inscrito un triángulo adornado de tres llamas, señala el misterio de la Trinidad, que tan intensamente había ocupado a S. Agrustír. Un reloj con sólo un segundero, puesto encima de un libro junto al tintero, significa otro de los problemas, cuya solución - según la leyenda - en vano buscaba: el de medir la eternídad. No aparece en el cuadro el tercer problema (¿pecado original? ¿libre albedrío?), - pero talvez no hay que tomar literalmente la inscripción Proverb. 30, 18: "Tria sunt difficilia mihi." - Tres cosas me son difíciles de saber.

De mucha antiguedad es el atributo "Martillo de la Herejía"; lo recibió por haber luchado contra numerosas sectas, que durante el curso de su vida pusieron en peligro a la unidad de la Iglesia Romana. 
3a-:

S. BONAVENTURA. DOCTORE (SIC) ECLESIE

(San Buenaventura, Doctor de la Iglesia)

- Leyenda a la derecha del cuadro -

S. Bonaven / tura, natione / Italus, Balne / oredij in Tus / cia ortus E / cclesiae Doc / tor Sera / phicus simul / et Cherubi / cus, quia in / flammat aff / ectum, et er / udit intelle / ctum.

TRAD.: San Buenaventura, Italiano de origen "nació en Bagnorea (Bagnoregio) Toscana; Doctor de la Iglesia, es un Serafín y Querubín a la vez, porque inflama el corazón $\theta$ instruye el intelecto.

El Santo, declarado por el Papa franciscano Sixto V Doctor seráfico, recibió al mismo tiempo que Santo Tomás el grado de doctor de la Universidad de París. Fué elegido Ministro general de la orden franciscana y creado, un año antes de su muerte, Cardenal-obispo de Albano. Una birreta junto al báculo de abad y la cruz de dos brazos indican sus altas funciones jerárquicas. Buenaventura representa aquella dirección dentro del Escolasticisme medieval Gque, inspirándose en el misticismo agustiniano, acoge también tendencias neo-platónicas. Un globo terrestre $\mathrm{y}$ diversos instrumentos de matemática en el cuadro aluden ingenuamente a sus estudios profundos para llegar a una conclusión sobre la composición de materia y forma y a sus ideas de filiación platónica, cuando en las esferas del Universo quiere reconocer imágenes y sombras de verdades superiores, a las que el hombre no llegará mediante la razón sino unica y directamente por la contemplación, porque: "Deus dedit Sapientiam et Scientiam" - Dios al hombre le da Sabiduría y Ciencia. Eclesiastés 2, 26. Y otra vez: "Quil docet hominem scientiam" - बquel que da la ciencia a los hombres. Salm. 93, 10.

Un reloj de arena y una calavera, sobre la que está escrita: "No mini parco" - No perdono a Nadie, - son símbolos de la vida ma nástica, en la que siempre va presente la idea de la muerte. El dedo del Santo, parece, va dirigido hacia una hostia milagrosa, que - se gún la tradición - recibió antes de morir. 


\section{3b-:}

\section{S. THOMAS DE AQVINO ECCL. DOCT. AN}

(Santo Tomás de Aquino, Doctor Angélico de la Iglesia)

- Leyenda a la izquierda del cuadro -

S. Thomas / Aquinas / Ecclesie / Doctor An / gelicus, ob / vite, et doc / trinae puri / tatem, nati / one fuit Ita / lus, patria / Neapolita / nus, ex nobi / lissima Co / mitum A / quinatum / prosapia/

TRAD.: Santo Tomás de Aquino, por la pureza de su vida como de su doctrina llamado el Doctor Angélico de la Iglesia; Italiano de origen, fué Nápoles su cuna, descendiendo él del muy noble linaje de los Candes de Aquino.

Brilla del pecho del sabio domínjico, en lugar de un pectoral, la imagen de la divina Sabiduría, un refulgentel disco solar. Amigo, pero a la vez antagonista filosófico de S. Buenaventura, recibió al mismo tiempo que éste, el magisterio de la Universidad de París, habiendo disertado sobre el tema quie leernos cen elecuadro: "Rigans montes de superioribus; de fructu operum tuorum litiabitur terra". - Tú riegas los montes con las aguas que envías de lo alto. Colmas la tierra de frutos que tú haces nacer. Salm. 103, 13.

Abierto sobre un atril se halla la obra máxima de su vida, la Suma contra Gentiles ("Summa totius' Theologiae in qua quidquid in universijs Biblijs continetur": La suma de toda la Teología en la que está contenida toda palabra que existe en la Biblia entera). Rechazó Sto. Tomás honores eclesiásticos, que le fueron ofrecidos como un arzobispado (véase las ínfulas en la mesa a sus espaldas); un angelito trata de fijar en la cabeza del santo una birreta cardenalicia. ¿Cuál era el propio premio, que se esperaba en recompensa de su esfuerzo gigante de componer una enciclopedia filosófico-teológica?. La respuesta nos la da el diálogo que sostiene con el Crucifijo. "Bene scripsisti de me, Thomas; tuam mercedem accipies," le dice Cristo. "Non aliam nisi te, Domine". Contesta Tomás. (Bien escribiste de mí, Tomás, recibirás tu recompensa. No otra, sino a tí mismo, Señor). 
4a-:

\section{S. MAGDALENA DE PAZZIS PASI NON MORI}

(Santa Magdalena dei Pazzi - Sufrir, no morir)

La santa, descendiendo de la noble familia florentina dei Pazzi (escudo fícticio de la casa en el estante de libros), era célebre por sus revelaciones, que en realidad nunca las escribía ella misma, sino que las dictaba, obedeciendo al mandado de sus autoridades monásticas. Sus presagios y sus visiones, que tratan sobre todo acerca de la Eucaristía ("Et verbum caro factum est" - Y el Verbo fué hecho Carne) forman una obra de carácter sorprendente en la literatura mística cristiana.

$$
4 b-\text { : }
$$

S. THERESIA A JESV AVT PATI AVT MORI

(Santa Teresa de Jesús - Sufrir o morir)

Un escudo fícticio indica el antiguo linaje de la gran monja de Avila, que en un arrebato de su alma de fuego exclama: "Iesu cor meum" - Jesús, Corazón mío, - para luego poner en movimiento su pluma ágil, que no solamente obras de valor místico, sino de belleza clásica regłalara a la Literatura Castellana. Su mentalidad infatigable a la que no asustaban los obstáculos, no toleraba las cosas imperfectas, ni las medidas a medias. Su alma de grandes ambiciones anhelaba el todo entero; de ahí la palabrascinAscendam in Salman et apprehendam fructus eius." Cant. 7,8 - Subiré a este palmero y cogeré sus frutos. ¿Y cuál es el fruto a que aspira? "Certamen forte Sapientiae" El certamen fuerte de la Sabiduría.

(Nota: no hay completa seguridad ni acerca del texto ni acerca del contenido de esta última línea, escrita sobre el borde de la mesa).

$$
\text { 5a一: }
$$

S. Ta CATARINA DE BOLONIA, RELIGIOSA DEL ORDEN DE

$$
\text { S. FRANCISCO }
$$

- Noticial biográfica dentro del cuadro -

S. ta / Catha / rina de Bolonia, Religi / osa del Orden de S.ta Clara / murio el dia 9 de Marso / de 1463 Cuio Cuerpo es / todo entero Canonisada / por Clemente XI año de 1712. 
La que antes de ingresar a la comunidad de las Clarisas franciscanas, era dama de corte de Margarita d'Este, se convirtió no solamente en monja ejemplar, sino en abadesa y autora de varios escritos místicos. A más de la cruz en su pecho, que traduce su alto rango monástico, lleva una medalla con la Asunción; y sujetado en el estante de libros vemos un pequeño lienzo con el retrato de un crucifijo - pues la santa había ejercido también la pintura y fué famosa por sus miniaturas. Leyenda que cubre en parte la corona: "Gloria eius in te videbitur" - Y en tí se dejará ver su gloria. Isajas 60.2.

\section{$5 b-$ :}

\section{SANTA CATALINA DE SENA DEL ORDEN DE PREDICADORES}

El cuadro que no ofrece ninguna noticia informativa, nos demuestra por una mancha negra aún existente, la magnitud del daño que debe haber sufrido anteriormente.

La figura de esta santa, - carácter decidido en un cuerpo frágil era de transcendental importancia en su época. Entre los corresponsales de su epistolario figuran papas, cardenales, príncipes. El cuadro nada de eso da a conocer, sólo enseña el ambiente sencillo de la celdía de una esposa de Cristo: la mesa con un crucifijo, una candela encendida, el tintero junto a cuadernos gruesos de apuntes, el lirio, flor de la castidad, la campana; del otro lado un estante de libros, la calavera, las disciplinas. Catalina recibio loscestigmas de Cristo. La corona de espinas que le viene ofrecida por un ángel, simboliza las torturas físicas a las que estaba sujeta durante toda su vida, pero sobre las que su poderoso ánimo triunfó.

$$
\text { 6a-: }
$$

\section{S. TA BRIGIDA, RELIGIOSA DEL ORDEN DE SAN BENITO ABAD}

La santa, por cuyas venas corrió dos veces sangre real, de pante del padre como de la madre, conoció la vida desde sus múltiples facetas: en el brillo de la corte del rey sueco Magno Érikson, en el matrimonio, durante el cual regaló a su esposo ocho hijos, en sus obras de caridad, las que la pusieron en contacto con la parte más miserable del pueblo, en los peregrinajes, viajes por cierto trabajosos 
y peligrosos en este tiempo y finalmente cuando murió su esposo. Tomó hábito y fundando varios órdenes, pasó casi todo el resto de su vida en Roma. Consérvase en San Paolo fuori le Mure el crucifijo que - según la tradición - le habló. Sus Revelaciones sobre la Pasión de Cristo, habiéndose traducidas al latín por su confesor, impresionaron al mundo de entonces. La leyenda dentro del cuadro representa un trocito sacado de ellas. (Por su mal estado de conservación no se reproduce sino la parte indubitable del párrafo):

"I en lib. cap. 70 Et pedes finaliter ad foramina su'a distenduntur cancellatique... et duobus clavis ad crucis stipitem per solidum... configuntur.".

TRAD.: Y finalmente son estirados los pies hasta los correspondientes aqujeros y... con dos clavos son sujetados al palo de la cruz... por came viva.

\section{S. GERTRUDIS MAGNA, ABBATISSA O. S. B.}

(L'a gran San Gertrudis, Abadesa del Orden de S. Benito)

El pintor - y no solamente él - confundió al la santa germana, que nunca había sido abadesa, con otras monjas de ese nombre y de verdadera rango de abadesas. Si entonces las lraves, la campana para convocar a la comunidad monacal, el báculo, deben su apariencia en el cuadro a un error del artista, no puede decirse lo mismo acenca de los anillos en la mesa, símbolo de los desponsorios. Tres ángeles tienden hacia ella un ciborio eucarístico, del que parte la leyenda: "Desponsabo" - Me desposaré, alusión a la unión mística de la Santa con Cristo. Constituían los temas predilectos de Gertrudis la santa humanidad de Cristo y la Eucaristía. El título de una de sus varias obras (introducidas al español por el monje benedictino Leandro de Granada) figura en el cuadro "Legatus Divine Pietatis" - Herencia de la Piedad divina. 
